\title{
Influence of SLS design requirements on the material consumption and self-weight of web-core sandwich panel FRP composite footbridges
}

\author{
Jordi UYTTERSPROT ${ }^{1, a}$, Wouter DE CORTE2, b* $^{*}$ and Bram INGELBINCK ${ }^{3, c}$ \\ 1 PhD fellow strategic basic research at FWO - Flanders, Host institution Department of Structural \\ Engineering and Building Materials, Faculty of Engineering and Architecture, Ghent University, Valentin \\ Vaerwyckweg 1, 9000 Ghent, Belgium \\ ${ }^{2}$ Associate professor, Department of Structural Engineering and Building Materials, Faculty of Engineering \\ and Architecture, Ghent University, Valentin Vaerwyckweg 1, 9000 Ghent, Belgium \\ ${ }_{3}^{3}$ Project Researcher C-Bridge, Department of Structural Engineering and Building Materials, Faculty of \\ Engineering and Architecture, Ghent University, Valentin Vaerwyckweg 1, 9000 Ghent, Belgium \\ aJordi.Uyttersprot@UGent.be,bWouter.DeCorte@UGent.be,cBram.Ingelbinck@UGent.be
}

* Corresponding author

Wouter De Corte

Laboratory Magnel-Vandepitte for Structural Engineering and Building Materials

Department of Structural Engineering and Building Materials

Faculty of Engineering and Architecture

Ghent University

Valentin Vaerwyckweg 1, 9000 Ghent, Belgium

Phone: $+32.479 / 31.81 .85$

email: Wouter.DeCorte@UGent.be 


\begin{abstract}
This paper reports a parametric study on the influence of the serviceability limit state design requirements on the material consumption and self-weight of web-core sandwich panel FRP composite footbridges. It describes the initial design process of a typical FRP web-core sandwich panel footbridge, focussing on the relevance of the various design checks on the overall material consumption at a given slenderness. It is clear that over a wide range of input parameters, only the SLS requirements are relevant for the design of this bridge type. Consequently, the final material consumption and achievable slenderness strongly depend on the code requirements. These requirements are non-uniform over various international codes, but are shown to have a huge influence on the material consumption. The final results heavily depend on the input value of the damping factor. In addition, human induced damping is not included in current design procedures, which may lead to a significant underestimation of the effective damping and consequently to over-design. The results contribute to understanding the mechanical behaviour of this promising bridge type, point to the relevance of the choice of SLS requirements in codes and to the lack of fully understanding the vibrational behaviour currently adopted in calculation models.
\end{abstract}

Keywords: FRP, Composite, Bridge Building, Analytical Design, Parametric Study

\title{
1 Introduction
}

Fibre reinforced polymers (FRP) or fibre polymer composites (FPC) show important potential for bridge construction [1-9]. For example, they are relatively stronger and lighter than classical building materials such as concrete and steel [10-12], they are more durable than timber and require less maintenance. Especially when looking at footbridges $[13,14]$, this type of material can offer an added value. In the context of the greening of the mobility $[15,16]$, these bridges will make up a much more important part of the public infrastructure in the future. However, the material also offers important advantages for road bridges for light and moderate traffic [17], for bridge decks [18-21], and for replacement and extension orders of existing bridges, such as the reuse of existing foundations and abutments and the limited installation time [22].

For bridges, typically synthetic thermoset polymers such as polyester will be used, as these have a low cost price, high durability and good stability in terms of creep [23]. Epoxy is only used when the mechanical properties of the structure are of great importance and when using fibres with high stiffnesses such as carbon fibres. For the reinforcement, unidirectional (UD) glass fibre fabrics are mainly used as they have a low cost price, high durability and offer the best stiffness properties in comparison to woven fabrics [24-26].

A significant portion of current FRP footbridges are so-called web-core sandwich panel bridges. In this bridge type, a flexurally rigid structural element is created through a sandwich construction comprising upper and lower FRP laminate flanges separated by a core material (e.g. PUR foam) [20,21]. However, due to the nature of the bridge application, the core material cannot resist all shear forces and concentrated local pressure forces and therefore requires to be complemented with longitudinal and in some cases transverse FRP webs, hence the denomination web-core sandwich panels. For this bridge type, the VARTM technique is used.

At the time of publishing of this paper, no standard or guideline on a European level regarding the design of FRP structures such as bridges is available, although a 'Technical Specification' [27] which should eventually become a Eurocode is in development. Several European countries have contributed to various guidelines for the design of FRP structures, such as EUROCOMP - Structural Design of Polymer Composites [28], CIRIA - Fibre-reinforced polymer bridges - guidance for designers [29] and BD90/05 - Design of FRP Bridges and Highway Structures [30]. In addition, 
the Dutch guideline CUR96:2019 - Fibre-reinforced plastics in structural and civil engineering supporting structures [31] provides the framework and calculation method for the constructional design of load-bearing FRP structures and will be used as the basis for the calculation of the GFRP web-core footbridge in this paper. The guideline applies to thermosetting FRPs with a fibre volume percentage of at least $15 \%$, consisting of either glass or carbon fibres in combination with an unsaturated polyester, vinylester or epoxy resin.

Nevertheless, little publicly available information provides guidance into the relevant influential factors in the design, especially the material consumption in relation to the overall dimensions, the slenderness, the presence of non-structural elements (surfacing, hand railing), and the design requirements.

In the first part of this paper, the theoretical background of the analytical calculation of a webcore GFRP footbridge is presented after which a preliminary design example in a realistic situation is given. Then, the results are discussed and a parametric study is presented, which proves that the design is almost purely serviceability limit state (SLS) driven, and consequently strongly depends on the code requirements. These requirements are non-uniform over various international codes, tender documents and manufacturer's recommendations. Most common is a limit value for the live load deformations, ranging from span/350 to span/100, typically. Without a doubt, the choice of this limit value has a significant impact on the achievable slenderness and material consumption.

In addition, comfort criteria based on the guideline 'Design of Lightweight Footbridges for Human Induced Vibrations' [32] may be imposed. In this guideline, a distinction is made between five traffic classes and two calculation procedures are presented to calculate the maximum expected vertical acceleration. In the SDOF Method, the dynamic behaviour of a structure can be evaluated by a modal analysis, where an arbitrary oscillation of the structure is described by a linear combination of several different harmonic oscillations in the natural frequencies of the structure. Therefore, the structure can be transformed into several different equivalent spring mass oscillators, each with a single degree of freedom (SDOF). In the Response Spectra Method, the stochastic loading and system response is described with a specific confidence level of $95 \%$. In this model it is assumed that the mean step frequency of the pedestrian stream coincides with the considered natural frequency of the bridge, the mass of the bridge is uniformly distributed, the mode shapes are sinusoidal, no modal coupling exists and the structural behaviour is linearelastic. The system response, for different pedestrian densities, is the characteristic acceleration, which is the 95th percentile of the maximum acceleration and is in the design check compared with the tolerable acceleration according to the comfort class to be proofed [32].

Based on the outcome, the bridge is classified into one of four comfort classes. To complete the calculation successfully, knowledge of the geometry, natural frequency, modal mass and damping ratio of the bridge is required. As will be shown, especially the applicable damping ratio is decisive for the material consumption. Unless damping values are based on testing, they should be taken in the range of 0,5 to $1,0 \%$ [31,32]. It will be demonstrated that following the current design method for vibrational comfort of footbridges, excessive material consumption combined with low achievable slendernesses will be achieved, based on these conservative values.

Most probably, these results do not reflect the true behaviour of web-core sandwich panel bridges as they profit from human induced damping [33-35]. However, as this is currently not incorporated into international standards or guidelines, and no definitive calculation method is available to take into account all effects, the authors of this paper cannot take human induced damping into account, but wish to point out the consequences of an approach based on current design guidelines on the material consumption and slenderness. As will be pointed out in the parametric study, they are quite detrimental.

Finally, the main findings of the parametric study are presented in the conclusion section. 
Figure 1 provides a graphical representation of the coherence of the various components in this paper and will be used as a guide.

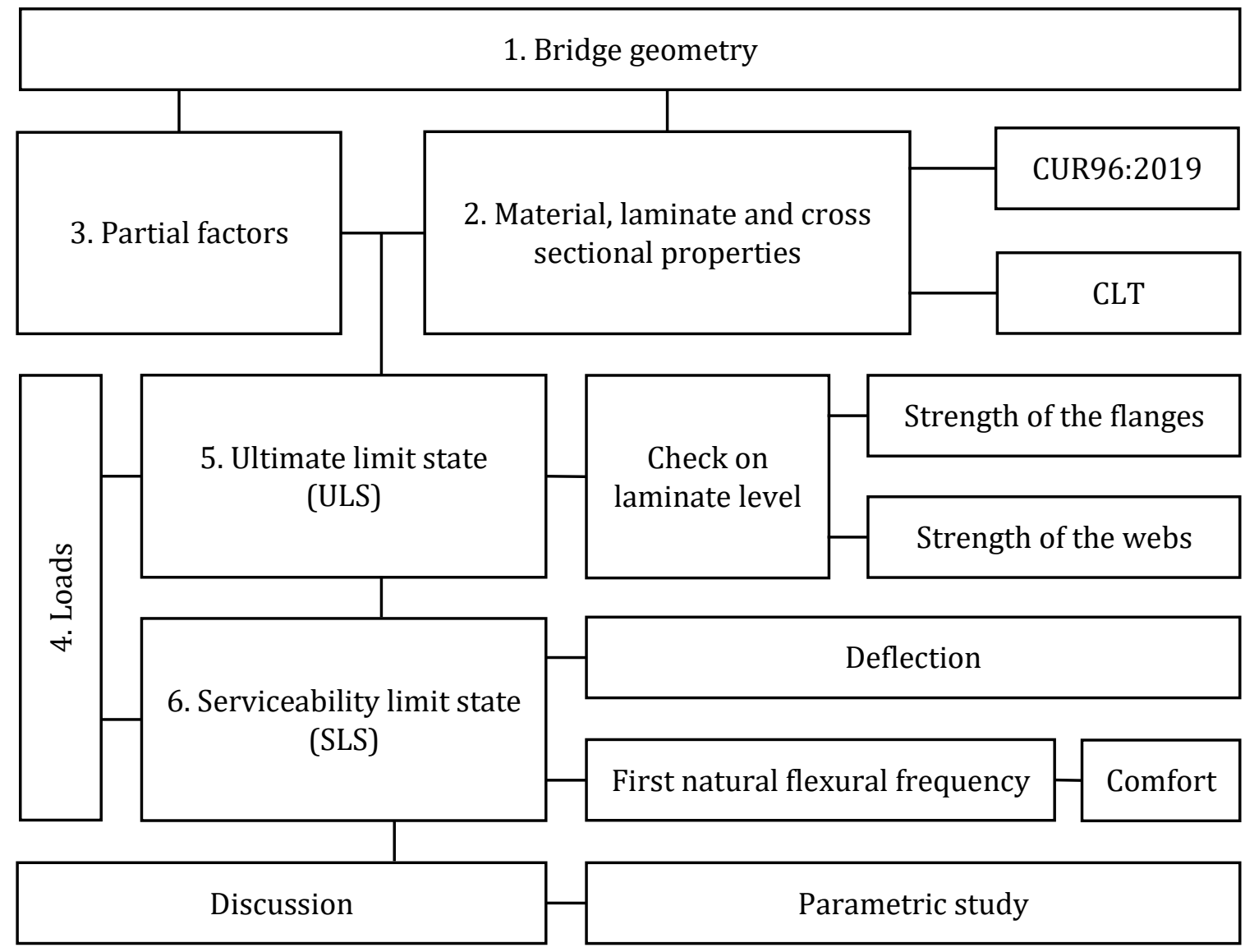

Figure 1: Schematic representation of the content of this paper

\section{Design model}

In this design model, a simply supported and double-sided clamped GRFP web-core bridge will be calculated. Basic input parameters, such as the length $L_{b}$, width $B_{b}$ and construction depth $\mathrm{H}_{b}$ of the bridge, and fixed values defined by standards and guidelines (i.e. material properties, partial factors and loads) will be used as starting points for the calculations and unity checks in ULS and SLS.

\subsection{Geometry}

The GFRP web-core footbridge will be supported on both sides on the abutments of width $\mathrm{L}_{\text {sup, }}$ from which the free span $L_{\text {span }}$ of the bridge can be calculated according to (1) as the distance between the central points of the supports. Moreover, the width of the bridge deck will be reduced on both sides by the width required for the anchoring of the handrail $\mathrm{B}_{\mathrm{fl}}$. According to (2), the useful width $B_{\text {use }}$ of the bridge used for the traffic loads can be calculated. Finally, (3) and (4) represent the total $\left(A_{b}\right)$ and useful area $\left(A_{\text {use }}\right)$ of the bridge deck.

$$
\begin{gathered}
L_{\text {span }}=L_{b}-L_{\text {sup }} \\
B_{\text {use }}=B_{b}-2 \cdot B_{f l} \\
A_{b}=L_{b} \cdot B_{b}
\end{gathered}
$$




$$
A_{\text {use }}=L_{b} \cdot B_{\text {use }}
$$

The bridge deck consists of a sandwich construction with a GFRP upper and lower flange with a respective thickness of $t_{u f}$ and $t_{1}$, separated by a PUR foam core. The upper and lower flange are connected by webs, with a thickness of $t_{w}$ and are evenly distributed over the width of the bridge deck with an intermediate distance $\mathrm{CTC}_{\mathrm{w}}$. The edge of the bridge deck can be constructed with a straight or chamfered edge and will accommodate the local force introduction due to the stainless steel handrail. Although the anchor detailing is not a part of the preliminary design, the thickness of the edges $\left(\mathrm{t}_{\mathrm{e}}\right)$ will be larger than that of the upper and lower flanges and will be included in the calculation of the self-weight of the bridge deck and the determination of the moment of inertia and consequently the bending stiffness of the bridge. The anchoring and the introduced forces of the handrail on the bridge deck will not be discussed in this paper.

Finally, on top of the upper flange and over the useful surface area of the bridge, a bituminous surfacing with a thickness $t_{s}$ is applied, which will also be included in the calculation of the permanent load on the bridge deck. The design lifespan for the bridge is 100 years as defined by EC1990 [36]. A schematic representation of the geometry and cross section of the GFRP web-core footbridge is given in Figure 2.
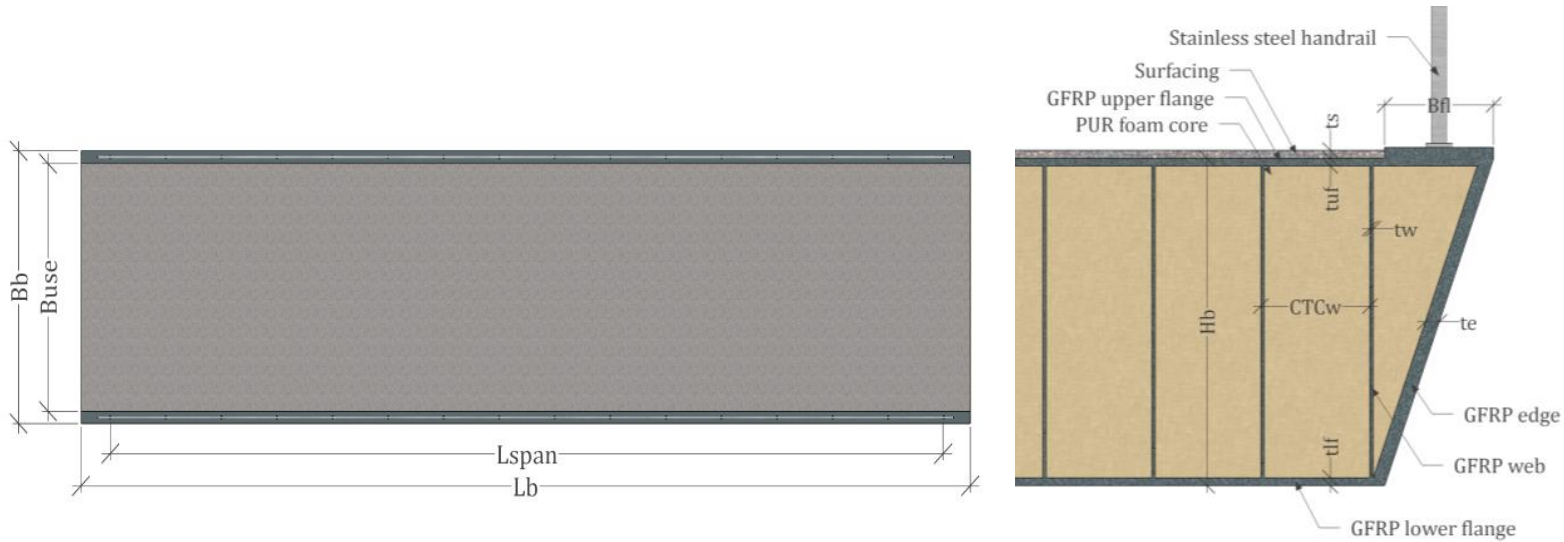

Figure 2: Detailed top and cross-sectional graphical representation of the dimensions and build-up of the design model

\subsection{Material, laminate and cross-sectional properties}

The laminates in the web-core GFRP footbridge are composed of E-glass fibres, a polyester matrix and multiple PUR foam cores. Table 1 provides the main properties of the constituent materials for the different parts of the bridge.

Table 1: Main properties of the constituent materials [31]

\begin{tabular}{|c|c|c|}
\hline Property & Symbol & Value \\
\hline \multicolumn{3}{|c|}{ E-Glass fibres } \\
\hline Density & $\rho_{\mathrm{f}}$ & $2570 \mathrm{~kg} / \mathrm{m}^{3}$ \\
\hline Longitudinal stiffness & $E_{f 1}$ & $73100 \mathrm{MPa}$ \\
\hline Poisson ratio & $\nu_{\mathrm{f} 1}$ & 0.24 \\
\hline Shear stiffness & $\mathrm{G}_{\mathrm{f}}$ & $30000 \mathrm{MPa}$ \\
\hline \multicolumn{3}{|c|}{ Polyester matrix } \\
\hline Density & $\rho_{\mathrm{m}}$ & $1200 \mathrm{~kg} / \mathrm{m}^{3}$ \\
\hline Logitudinal stiffness & $\mathrm{E}_{\mathrm{m}}$ & $3550 \mathrm{MPa}$ \\
\hline Poisson ratio & $v_{\mathrm{m} 12}$ & 0.38 \\
\hline Shear stiffness & $\mathrm{G}_{\mathrm{m}}$ & $1350 \mathrm{MPa}$ \\
\hline Glass transition temperature & $\mathrm{T}_{\mathrm{g}}$ & $60-100^{\circ} \mathrm{C}$ \\
\hline
\end{tabular}




\begin{tabular}{lcc}
\multicolumn{3}{c}{ PUR foam core } \\
Density & $\rho_{\text {core }}$ & $50 \mathrm{~kg} / \mathrm{m}^{3}$ \\
\hline
\end{tabular}

For the production of the bridge, the vacuum assisted resin transfer moulding (VARTM) [37] technique is used, aiming for a fibre volume percentage $\left(V_{f}\right)$ of the resulting laminates between 50 and $60 \%$. The density of the composite material E-glass/polyester can be calculated based on the rule of mixture and the densities displayed in Table 1 for the fibres and matrix.

$$
\rho_{c}=V_{f} \cdot \rho_{v}+\left(1-V_{f}\right) \cdot \rho_{m}
$$

Multi-axial glass reinforcement fabrics, consisting of different unidirectional (UD) layers joined together, are typically used for the construction of the various laminates of the bridge. The properties of a single layer can be calculated using the formulas of Halpin-Tsai [38-40] and the proposed fibre volume percentage. The longitudinal $\left(E_{1}\right)$ and transverse stiffness $\left(E_{2}\right)$, the shear stiffness $\left(\mathrm{G}_{12}\right)$ and the Poisson ratio in the laminate plane $\left(v_{12}\right)$ can be calculated using the mechanical properties of the fibres and matrix stated in Table 1.

$$
\begin{gathered}
E_{1}=\left[E_{f 1} \cdot V_{f}+E_{m} \cdot\left(1-V_{f}\right)\right] \cdot \phi_{U D} \\
E_{2}=\left[\frac{1+\xi_{2} \eta_{2} V_{f}}{1-\eta_{2} V_{f}} \cdot E_{m}\right] \cdot \phi_{U D} \quad \text { with } \eta_{2}=\frac{\left(E_{f 2} / E_{m}-1\right)}{\left(E_{f 2} / E_{m}+\xi_{2}\right)} \quad \text { with } \xi_{2}=2 \\
G_{12}=\left[\frac{1+\xi_{G} \eta_{G} V_{f}}{1-\eta_{G} V_{f}} \cdot G_{m}\right] \cdot \phi_{U D} \quad \text { with } \eta_{G}=\frac{\left(G_{f} / G_{m}-1\right)}{\left(G_{f} / G_{m}+\xi_{G}\right)} \quad \text { with } \xi_{G}=1 \\
v_{12}=v_{f} \cdot V_{f}+v_{m} \cdot\left(1-V_{f}\right)
\end{gathered}
$$

The estimations for $E_{2}$ using these equations strongly depend on the value of the reinforcement parameter $\xi_{2}$ which takes into account the geometry and spatial distribution of the reinforcement. It is common practice to use a value of $\xi_{2}=2$ for the calculation of $\mathrm{E}_{2}$ using the $\mathrm{H}-\mathrm{T}$ equations, despite a scientific study proposing a value of 1.5 to obtain more truthful results for $\mathrm{E}_{2}$ [41]. $\phi_{U D}$ is an empirical reduction coefficient equal to 0.97 [31].

\subsubsection{Laminate stiffness}

The characteristic values of the laminate stiffness are calculated on the basis of the classic laminate theory (CLT) [42] in a composite calculator software program such as eLamX ${ }^{2}$ [43] or in an Excel sheet in which the above characteristic lamella properties of a UD lamella are maintained. The equivalent stiffness of the laminates is derived from the ABD matrix of the CLT, calculated as shown below.

$$
E_{x}=\frac{1}{t_{\text {lam }}} \cdot\left(A_{11}-\frac{A_{12}^{2}}{A_{22}}\right) \quad E_{y}=\frac{1}{t_{\text {lam }}} \cdot\left(A_{22}-\frac{A_{12}^{2}}{A_{11}}\right) \quad G_{x y}=\frac{A_{66}}{t_{\text {lam }}}
$$

\subsubsection{ULS laminate strength}

For GFRPs with at least $12.5 \%$ of the fibre reinforcement in each main direction, the in-plane strength of the laminate in the ultimate limit state (ULS) in each direction, for (flexural) tension, compression and shear, can be calculated using a simplified strain based criterion. This is a linear strain limit of $1.2 \%$ in tension and compression, both parallel and transverse to the loading 
direction and a shear strain limit of $1.6 \%$ under a uniaxial stress condition or pure shear, according to CUR96:2019 [31].

$$
f_{x t, R k}=f_{x c, R k}=1,2 \% \cdot E_{x} \quad f_{y t, R k}=f_{y c, R k}=1,2 \% \cdot E_{y} \quad \tau_{x y, R k}=1,6 \% \cdot G_{x y}
$$

\subsection{Partial factors}

According to CUR96:2019 [31], the design value of the resistance $R_{d}$ and of a material or product property $\mathrm{X}_{\mathrm{d}}$ must be calculated with the following formula, including conversion $\left(\eta_{c}\right)$ and material factors $\left(\gamma_{M}\right)$.

$$
R_{d}=\frac{\eta_{c} \cdot R_{k}}{\gamma_{M}} \quad X_{d}=\frac{\eta_{c} \cdot X}{\gamma_{M}}
$$

The material factor $\gamma_{M}$ for an FRP laminate or construction consists of two parts. A partial material factor $\gamma_{\mathrm{M} 1}$ linked to the geometric deviations and model uncertainties, depending on the way in which the lamella or laminate properties are determined or derived and a partial material factor $\gamma_{\mathrm{M} 2}$ that takes into account the uncertainties in the strength properties of the material, depending on the distribution of the material properties.

$$
\gamma_{M}=\gamma_{M 1} \cdot \gamma_{M 2}
$$

In this design model, the lamella and laminate properties are determined on the basis of theoretical models, as already shown above. As a result, the partial material factors for the geometric deviations and model uncertainties $\gamma_{\mathrm{M} 1}$ for the specific resistance according to CUR96:2019 [31] are shown in Table 2. Furthermore, it can be assumed in the preliminary design that the VARTM technique is used for the production of the bridge, so that the coefficient of variation on the stress level $V_{x} \leq 0.10$ is achieved. The partial material factor for the uncertainties in the strength properties $\gamma_{\mathrm{M} 2}$ for the specific resistance according to CUR96:2019 [31] is shown in Table 2. These values can be used in the case of post-hardened laminates, where the resin properties set in the design phase have been realized before commissioning of the construction, with respect to $\mathrm{T}_{\mathrm{g}}$. The resulting partial material factor $\gamma_{\mathrm{M}}$ calculated according to equation (13) in the ULS for the specific resistance is given in Table 2. In the serviceability limit state (SLS), the partial material factor $\gamma_{\mathrm{M}}$ is equal to 1.00 .

Table 2: Partial material factor for the specific resistance [31]

\begin{tabular}{cccc}
\hline & Strength & Local stiffness & Global stiffness \\
\hline $\boldsymbol{\gamma}_{\mathrm{M} 1}$ & 1.35 & 1.15 & 1.15 \\
$\boldsymbol{\gamma}_{\mathrm{M} 2}$ & 1.20 & 1.40 & 1.35 \\
$\boldsymbol{\gamma}_{\mathrm{M}, \mathrm{ULS}}$ & 1.62 & 1.61 & 1.55 \\
$\boldsymbol{\gamma}_{\mathrm{M}, \mathrm{SLS}}$ & 1.00 & 1.00 & 1.00 \\
\hline
\end{tabular}

In addition to the partial material factor $\gamma_{\mathrm{M}}$, a conversion factor $\eta_{\mathrm{c}}$ will also be taken into account to include the effects of environmental factors and aging. This conversion factor takes into account the temperature effects $\eta_{c t}$, effects of water (vapour) $\eta_{c m}$, effects of creep $\eta_{c v}$ and effects of fatigue $\eta_{\mathrm{cf}}$.

$$
\eta_{c}=\eta_{c t} \cdot \eta_{c m} \cdot \eta_{c v} \cdot \eta_{c f}
$$

Since the glass transition temperature $\left(\mathrm{T}_{\mathrm{g}}\right)$ of a polyester is between 60 and $100^{\circ} \mathrm{C}$, the maximum operating temperature $\left(\mathrm{T}_{\mathrm{d}}\right)$ at the top flange of the bridge during full insulation will be in the range $\mathrm{T}_{\mathrm{g}}-40^{\circ} \mathrm{C}<\mathrm{T}_{\mathrm{d}} \leq \mathrm{T}_{\mathrm{g}}-20^{\circ} \mathrm{C}$, so that the conversion factor for the temperature effects for both the 
ULS and SLS is equal to 0.9 according to CUR96:2019 [31]. In practice, a $\mathrm{T}_{\mathrm{g}}$ of at least $80^{\circ} \mathrm{C}$ is typically required for bridges.

Secondly, the conversion factor for the effects of water (vapour) is also equal to 0.9 in ULS and SLS, since the bridge will be exposed to varying environmental conditions, where dry and wet periods alternate.

For an anisotropic GFRP laminate constructed from UD-layers of E-glass fibres and a polyester resin with $55 \%$ fibres in the $0^{\circ}$ direction and $15 \%$ fibres in the other three main directions, a conversion factor for the effects of creep can be expected of 0.70 for a service life of 100 years. Since the construction of the upper and lower flanges is in accordance with the statement above of CUR96:2019, the prescribed value for the conversion factor $\eta_{\mathrm{cv}}$ can be used in the preliminary design model.

Lastly, according to CUR96:2019 [31], fatigue must be taken into account if the load varies cyclically and the number of expected fatigue load changes is greater than 5000 or if the absolute maximum of the cyclic load is greater than $40 \%$ of the maximal load. Since the design model describes a footbridge, no fatigue load is assumed to be present during the service life of the bridge, resulting in no stiffness loss for the GFRP laminates due to fatigue. The conversion factor for fatigue will therefore be equal to 1.00 .

Table 3 summarises the different conversion factors for the assessment aspects that will be used in the preliminary design model.

Table 3: Conversion factors for the different assessment aspects in ULS and SLS [31]

\begin{tabular}{llccccc}
\hline & \multicolumn{5}{c}{ Assessment aspect } & \multicolumn{4}{c}{ Conversion factor } \\
\cline { 2 - 6 } & & $\boldsymbol{\eta}_{\mathbf{c t}}$ & $\boldsymbol{\eta}_{\mathbf{c m}}$ & $\boldsymbol{\eta}_{\mathbf{c v}}$ & $\boldsymbol{\eta}_{\mathbf{c f}}$ & $\boldsymbol{\eta}_{\mathbf{c}}$ \\
\hline ULS & Strength under quasi permanent loading $\left(\eta_{\mathrm{cl}, \mathrm{s}}\right)$ & 0.90 & 0.90 & 0.70 & - & $\mathbf{0 . 5 6 7}$ \\
& Strength under short-term load $\left(\eta_{\mathrm{cs}, \mathrm{s}}\right)$ & 0.90 & 0.90 & - & - & $\mathbf{0 . 8 1 0}$ \\
& Stability $\left(\eta_{\mathrm{c}, \mathrm{stab}}\right)$ & 0.90 & 0.90 & 0.70 & 1.00 & $\mathbf{0 . 5 6 7}$ \\
& Fatigue $\left(\eta_{\mathrm{c}, \mathrm{f}}\right)$ & 0.90 & 0.90 & - & - & $\mathbf{0 . 8 1 0}$ \\
SLS & Strength under quasi permanent loading $\left(\eta_{\mathrm{cl}, \mathrm{d}}\right)$ & 0.90 & 0.90 & 0.70 & 1.00 & $\mathbf{0 . 5 6 7}$ \\
& Strength under short-term load $\left(\eta_{\mathrm{cs}, \mathrm{d}}\right)$ & 0.90 & 0.90 & - & - & $\mathbf{0 . 8 1 0}$ \\
& Vibrations under quasi permanent loading $\left(\eta_{\mathrm{cl}, \mathrm{t}}\right)$ & 0.90 & 0.90 & - & 1.00 & $\mathbf{0 . 8 1 0}$ \\
& Vibrations under short-term load $\left(\eta_{\mathrm{cs}, \mathrm{t}}\right)$ & 0.90 & 0.90 & - & - & $\mathbf{0 . 8 1 0}$ \\
Damage $\left(\eta_{\mathrm{c}, \mathrm{dam}}\right)$ & 0.90 & 0.90 & 0.70 & 1.00 & $\mathbf{0 . 5 6 7}$ \\
\hline
\end{tabular}

\section{$2.4 \underline{\text { Loads }}$}

The design and calculation of FRP structures is based on loads according to EN1991-2 [44] and load combinations and partial load factors in compliance with EN1990 [36]. The loads can be subdivided in three categories: permanent loads, traffic loads and accidental loads. In this design model, only the strength of the flanges and web plates under quasi-permanent and short-term loading will be examined in the ULS. In the SLS, the deformations and the vibrations (comfort) will be checked under quasi-permanent and short-term loading.

\subsubsection{Permanent loads}

The permanent loads on the bridge consist of the self-weight $q_{S W}$ of the structural parts and nonstructural surfacing and of auxiliary elements such as a handrail, which can be calculated on the basis of the densities stated in Table 1 and the geometry of Figure 2.

\subsubsection{Traffic loads}

The traffic loads are listed in Table 4. Unlisted loads do not apply or are not considered normative and are therefore not included in the design and calculations. 
Table 4: Traffic loads on GFRP web-core footbridge

Uniformly distributed load [EN1991-2 5.3.2.1]

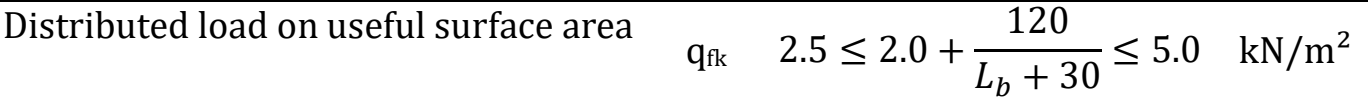

Concentrated load [EN1991-2 5.3.2.2]

$\begin{array}{llcc}\text { Concentrated load } & \mathrm{Q}_{\mathrm{fvd}} & 10 & \mathrm{kN}\end{array}$

Loading area

$\begin{array}{lll}\mathrm{B}_{\mathrm{fvd}} & 0.10 \quad \mathrm{~m}\end{array}$

Service vehicle [EN1991-2 5.3.2.3]

2 axle load groups

Wheel base

$\mathrm{Q}_{\mathrm{sv}} \quad 25.00 \quad \mathrm{kN}$

Track width

$\begin{array}{lll}\mathrm{L}_{\mathrm{sv}} & 3.00 & \mathrm{~m}\end{array}$

Side length of contact area

Horizontal forces [EN1991-2 5.4]

$\begin{array}{lll}\mathrm{B}_{\mathrm{sv}} & 1.30 \quad \mathrm{~m}\end{array}$

\begin{tabular}{lccc}
$\begin{array}{l}\text { For uniformly distributed load } \\
\text { For service vehicle }\end{array}$ & $\mathrm{Q}_{\mathrm{flk} 0}$ & $0.1 . q_{f k} \cdot B_{u s e} \cdot L_{b}$ & $\mathrm{kN}$ \\
Pedestrian traffic [EUR 23984 EN 4.3.1] & $\mathrm{Q}_{\mathrm{flk} 1}$ & $0.6 \cdot\left(2 \cdot Q_{s v}\right)$ & $\mathrm{kN}$ \\
\hline $\begin{array}{l}\text { Weight of one person } \\
\text { Pedestrian density }\end{array}$ & $\mathrm{P}$ & 800.00 & $\mathrm{~N}$ \\
\hline $\mathrm{d}_{\mathrm{TC}}$ & $0.1 / 0.2 / 0.5 / 1.0 / 1.5$ & $\mathrm{P} / \mathrm{m}^{2}$
\end{tabular}

\subsubsection{Accidental loads}

The accidental loads are listed in Table 5. Unlisted loads do not apply or are not considered normative and are therefore not included in the design and calculations.

Table 5: Accidental loads on GFRP web-core footbridge

Unintentional vehicle [EN1991-2 5.6.3]

$\begin{array}{llcl}\text { Front axle load } & \mathrm{Q}_{\mathrm{uv} 1} & 80.00 & \mathrm{kN} \\ \text { Back axle load } & \mathrm{Q}_{\mathrm{uv} 2} & 40.00 & \mathrm{kN} \\ \text { Wheel base } & \mathrm{L}_{\mathrm{uv}} & 3.00 & \mathrm{~m} \\ \text { Track width } & \mathrm{B}_{\mathrm{uv}} & 1.30 & \mathrm{~m} \\ \text { Contact area of side } & \mathrm{B}_{\mathrm{uv}, \mathrm{w}} & 0.20 & \mathrm{~m} \\ \text { Horizontal forces for unintentional vehicle } & \mathrm{Q}_{\mathrm{flk} 2} & 0.6 \cdot\left(Q_{u v 1}+Q_{u v 2}\right) & \mathrm{kN}\end{array}$

\subsubsection{Load combinations}

The list below shows the normative load combinations for pedestrian and bicycle bridges, based on EN1990 [36]. The SLS check is performed with combinations 1, 3 and 4. The ULS check is performed with load combinations 3, 4, 5 and 6. It is assumed that the other combinations mentioned in the Eurocodes do not apply or are less relevant for the ULS and SLS checks in the construction, i.e. LC1 and LC2 [36].
Load combination 3
Permanent load + Uniformly distributed load + Horizontal forces for uniformly distributed load
Load combination 4
Permanent load + Uniformly distributed loads $\left(\psi_{4 \mathrm{q}}=0.8\right)+$ Service vehicle + Horizontal forces for uniformly distributed load and service vehicle
Load combination 5 Permanent load + Concentrated load
Load combination 6
Permanent load + Unintentional vehicle + Horizontal forces for unintentional vehicle

\subsection{Ultimate limit state (ULS)}

Due to the occurrence of creep, different conversion factors for long-term loads, under quasi permanent loading, and short-term loads apply for the assessment in the ULS. For a combined 
assessment of long-term load and short-term variable load, both the capacity of the laminate or cross-section of the bridge used by long-term and the short-term load must be accounted for with the corresponding conversion factors shown in Table 3.

$$
\sum_{i \geq 1}\left(\frac{E_{d, i}}{R_{d, i}}\right)_{q p}+\sum_{j \geq 1}\left(\frac{E_{d, j}}{R_{d, j}}\right)_{s t} \leq 1
$$

In the design model, the strength of the flanges and web plates is assessed at laminate level for the decisive load combinations by using the simplified strain criterion.

\subsubsection{Strength of the flanges}

For the simply supported or clamped structures, the dominant stresses in the flanges will be caused by longitudinal bending, creating tensile and compressive stresses in the lower and upper flange, respectively. Due to the small thickness of the laminates of the flanges in relation to the thickness of the bridge deck, shear stresses will only make up a small part of their total stress pattern. As a result, the stresses in the flanges can be considered as uniform longitudinal stresses. The longitudinal stresses in the flanges are tested in load combinations 3,4 and 6 as shown below.

\section{Flexure (simply supported)}

by self-weight

by uniformly distributed load

$$
M_{S W}=\frac{1}{8} \cdot q_{S W} \cdot B_{b} \cdot L_{\text {span }}{ }^{2}
$$

$$
M_{q}=\frac{1}{8} \cdot q_{f k} \cdot B_{u s e} \cdot L_{\text {span }}{ }^{2}
$$

by service vehicle

by unintended vehicle

$$
M_{s v}=\frac{1}{4} \cdot 2 Q_{s v} \cdot L_{s p a n}
$$

$$
M_{u v}=\frac{1}{4} \cdot\left(Q_{u v 1}+Q_{u v 2}\right) \cdot L_{\text {span }}
$$

\section{Load combinations}

LC3

LC4

$$
M_{L C 3}=\gamma_{M, U L S} \cdot\left(\frac{\gamma_{G, U L S}}{\eta_{c l, S}} \cdot M_{S W}+\frac{\gamma_{Q, U L S}}{\eta_{c S, S}} \cdot M_{q}\right)
$$

LC6

$$
M_{L C 4}=\gamma_{M, U L S} \cdot\left(\frac{\gamma_{G, U L S}}{\eta_{c l, S}} \cdot M_{S W}+\frac{\gamma_{Q, U L S}}{\eta_{c S, S}} \cdot M_{s v}\right)
$$

Decisive combination

$$
M_{L C 6}=\gamma_{M, U L S} \cdot\left(\frac{\gamma_{G, U L S}}{\eta_{c l, S}} \cdot M_{S W}+\frac{\gamma_{A, U L S}}{\eta_{c s, S}} \cdot M_{u v}\right)
$$

$$
M_{\max }=\max \left\{M_{L C 3} ; M_{L C 4} ; M_{L C 6}\right\}
$$

\section{Stresses}

\section{In upper flange}

In lower flange

$$
\sigma_{x, \mathrm{uf}, M}=\frac{M_{\max } \cdot y_{h 0}}{I_{x, f}}
$$

Unity check

$$
\sigma_{x, \mathrm{lf}, M}=\frac{M_{\max } \cdot y_{h 1}}{I_{x, f}}
$$




$$
\begin{aligned}
& \text { Upper flange } \\
& \text { Lower flange } \\
& \qquad u c_{\sigma, x, \mathrm{uf}}=\frac{\sigma_{x, \mathrm{uf}, M}}{f_{x c, R k, \mathrm{u} f}} \leq 1 \\
& \text { In the example hereafter, it will be demonstrated that the strength of the upper and lower flange } \\
& \text { is typically not decisive in the design of GFRP footbridges, due to the specific material properties }
\end{aligned}
$$

of GFRP materials, especially the high strength-to-stiffness ratio.

\subsubsection{Strength of the web plates}

The shear strength of the webs is checked for load combinations 3, 4 and 6 . Each web is considered to be the thin-walled web of an I-beam with wide flanges, thus shear stress in the webs is considered constant over the web depth.

In load combination 3 under quasi permanent load, all web plates are considered to be loadbearing $\left(\mathrm{n}_{\mathrm{w}, \mathrm{tot}}\right)$. In load combinations 4 and 6 , only the web plates directly under the wheel prints are considered for each wheel $\left(\mathrm{n}_{\mathrm{w}, \mathrm{sv}}\right)$. The edges of the bridge are not included in this calculation, so the calculation is conservative.

\section{Shear forces (simply supported)}

by self-weight

$$
V_{S W}=\frac{1}{2} \cdot q_{S W} \cdot C T C_{w} \cdot L_{\text {span }}
$$

by uniformly distributed load

by service vehicle

$$
V_{q}=\frac{1}{2} \cdot q_{f k} \cdot C T C_{w} \cdot L_{\text {span }}+\frac{Q_{f l k 0} \cdot H_{b}}{n_{w, t o t} \cdot L_{\text {span }}}
$$

$$
V_{s v}=\frac{1}{2 n_{w, s v}} \cdot\left[Q_{s v} \cdot\left(2-\frac{L_{s v}}{L_{s p a n}}\right)+\frac{Q_{f l k 1} \cdot H_{b}}{L_{s p a n}}\right]
$$

by unintended vehicle

$$
V_{u v}=\frac{1}{2 n_{w, s v}} \cdot\left[Q_{u v 1}+Q_{u v 2} \cdot\left(1-\frac{L_{u v}}{L_{\text {span }}}\right)+\frac{Q_{f l k 2} \cdot H_{b}}{L_{\text {span }}}\right]
$$

\section{Load combinations}

LC3

LC4

$$
V_{L C 3}=\gamma_{M, U L S} \cdot\left(\frac{\gamma_{G, U L S}}{\eta_{c l, S}} \cdot V_{S W}+\frac{\gamma_{Q, U L S}}{\eta_{c S, S}} \cdot V_{q}\right)
$$

LC6

$$
V_{L C 4}=\gamma_{M, U L S} \cdot\left(\frac{\gamma_{G, U L S}}{\eta_{c l, S}} \cdot V_{S W}+\frac{\gamma_{Q, U L S}}{\eta_{c s, S}} \cdot V_{s v}\right)
$$

Decisive combination

$$
V_{L C 6}=\gamma_{M, U L S} \cdot\left(\frac{\gamma_{G, U L S}}{\eta_{c l, S}} \cdot V_{S W}+\frac{\gamma_{A, U L S}}{\eta_{c S, S}} \cdot V_{u v}\right)
$$

$$
V_{\text {max }}=\max \left\{V_{L C 3} ; V_{L C 4} ; V_{L C 6}\right\}
$$

\section{Geometric properties}

Surface area web plate

$$
A_{w}=\left(H_{b}-\frac{t_{u f}}{2}-\frac{t_{l f}}{2}\right) \cdot t_{w}
$$

\section{Shear stresses}

in web plate 


$$
\begin{array}{cc}
\hline & \tau_{x y, \mathrm{w}, \mathrm{V}}=\frac{V_{\max }}{A_{w}} \\
\text { Unity check } & u c_{\tau, x y, \mathrm{w}}=\frac{\tau_{x y, \mathrm{w}, \mathrm{V}}}{\tau_{x y, R k, \mathrm{w}}} \leq 1
\end{array}
$$

The compressive strength of the webs loaded by direct force introduction is assessed in load combination 5. A strip with one web plate in the middle and a width equal to the centre to centre distance of the web plates is considered.

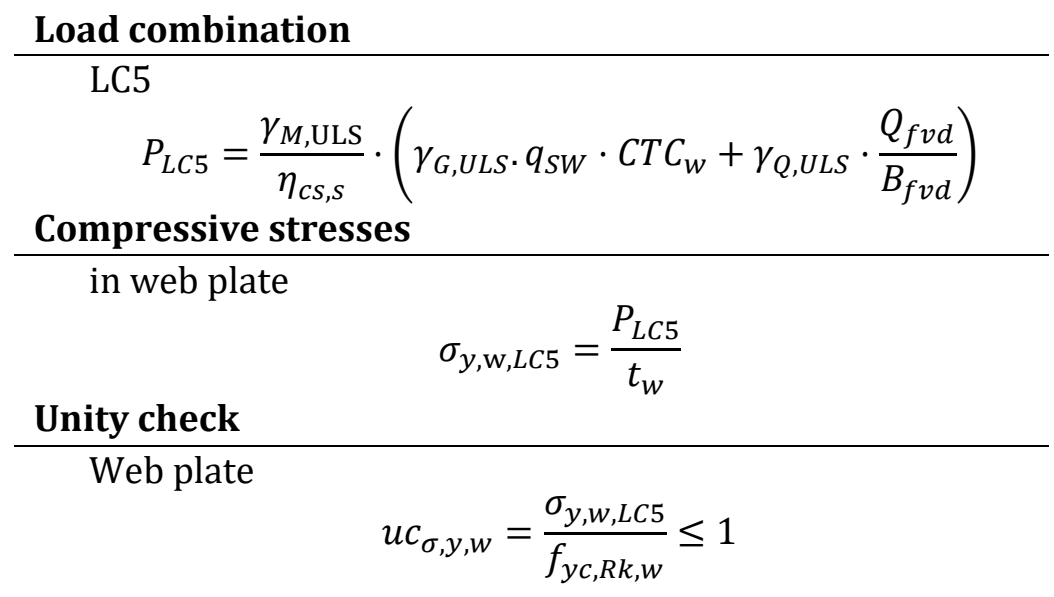

In the example hereafter, it will be demonstrated that the shear and compressive strength of the webs typically does not pose a problem in the design of a GFRP web-core footbridge.

\subsection{Serviceability limit state (SLS)}

In the SLS, the effects of the environmental conditions and aging on the stiffness of the material must be taken into account through the conversion factors stated in Table 3 . In this analytical design model, the bridge is simplified to a simply supported or clamped beam at both sides. For the SLS assessment, the following criteria apply .

- A minimum first natural flexural frequency of $3.00 \mathrm{~Hz}$ in unloaded condition under the influence of environmental vibrations as a result of, for example, wind and traffic;

- A minimum first natural flexural frequency of $2.2 \mathrm{~Hz}$ under pedestrian traffic, so that the comfort requirements for pedestrian bridges can be met at a later stage;

- A maximum deflection of $\mathrm{w}_{\max }=\mathrm{L}_{\mathrm{b}} /$ limit due to traffic loads. This limit value is typically specified by the client, typically values of 100 to 350 are prescribed.

\subsubsection{Deflection}

The deflection at midspan $\left(\mathrm{w}_{\mathrm{tot}}\right)$ can be calculated using beam formulas, where the deflection due to shear cannot be neglected. As an example, equation (16) gives the deflection for a simply supported beam with a span L, loaded by a uniformly distributed load q.

$$
w_{t o t}=\frac{5}{384} \frac{q \cdot L^{4}}{\sum_{i} E_{i} I_{i}}+\frac{1}{8} \frac{q \cdot L^{2}}{\sum_{i} G_{i} A_{i}}
$$

Deflection due to the uniformly distributed load in load combination 3:

$$
w_{L C 3}=\frac{5}{384} \frac{\gamma_{M, S L S} \cdot \gamma_{G, S L S} \cdot q_{f k} \cdot B_{u s e} \cdot L_{s p a n}{ }^{4}}{E I_{x} \cdot \eta_{c s, d}}+\frac{1}{8} \frac{\gamma_{M, S L S} \cdot \gamma_{G, S L S} \cdot q_{f k} \cdot B_{u s e} \cdot L_{s p a n}{ }^{2}}{G A_{x y} \cdot \eta_{c s, d}}
$$

Deflection due to the service vehicle in load combination 4: 


$$
\begin{gathered}
w_{L C 4}=\frac{1}{48} \frac{\gamma_{M, S L S} \cdot \gamma_{Q, S L S} \cdot Q_{s v} \cdot\left(L_{s p a n}-L_{s v}\right)}{E I_{x} \cdot \eta_{c s, d}} \cdot\left[2 \cdot L_{s p a n} \cdot\left(L_{s p a n}+L_{s v}\right)-L_{s v}^{2}\right] \\
+\frac{1}{4} \frac{\gamma_{M, S L S} \cdot \gamma_{Q, S L S} \cdot Q_{s v} \cdot L_{s p a n}}{G A_{x y} \cdot \eta_{c s, d}}
\end{gathered}
$$

Unity check:

$$
u c_{w_{L C 3}}=\frac{w_{L C 3}}{w_{\max }} \leq 1 \quad u c_{w_{L C 4}}=\frac{w_{L C 4}}{w_{\max }} \leq 1
$$

\subsubsection{First natural flexural frequency}

The bridge will be simplified as a simply supported or double clamped beam, for which the first natural flexural frequency can be calculated with the following formula. When determining the first natural flexural frequency of the GFRP footbridge, the mass of the load causing the vibration must be included in the assessment if this mass exceeds $5 \%$ of the self- weight of the bridge structure [31].

$$
f\left(K_{n} ; d_{T C}\right)=\frac{K_{n}}{2 \pi} \sqrt{\frac{E I_{x} \cdot g}{\gamma_{M, S L S} \cdot\left[q_{S W} \cdot B / \eta_{c l, t}+d_{T C} \cdot P \cdot B_{u s e} / \eta_{c s, t}\right] \cdot L_{s p a n}{ }^{4}}}
$$

In this formula, $\mathrm{K}_{\mathrm{n}}$ is a constant that depends on the boundary conditions of the bridge. It is equal to 9.87 for a simply supported beam and equal to 22.4 for a double clamped bridge [31].

Unity check:

$$
u c_{f_{0, \text { load }}}=\frac{f_{\text {min,load }}}{f_{0, \text { load }}} \leq 1 \quad u c_{f_{0, \text { unload }}}=\frac{f_{\text {min, unload }}}{f_{0, \text { unload }}} \leq 1
$$

The first natural flexural frequency will be determined for an unloaded bridge and for a bridge loaded with a varying pedestrian traffic. The former is important for vibrations due to traffic in the vicinity of the bridge and wind so that they cannot cause unacceptable displacements and vibrations of the bridge. The latter is important for the comfort of the pedestrians on the bridge.

The comfort of the bridge will be assessed based on the maximum vertical acceleration of the bridge under a pedestrian traffic. The scientific and technical report for the Design of Lightweight

\begin{tabular}{|c|c|c|}
\hline $\begin{array}{l}\text { Traffic } \\
\text { class }\end{array}$ & $\mathbf{d}_{\mathrm{TC}}\left[\mathbf{P} / \mathbf{m}^{2}\right]$ & Characteristics \\
\hline TC1 & $\min \left\{\frac{15}{A_{\text {use }}} ; 0.1\right\}$ & Very weak traffic: Group of 15 people spread over the bridge. \\
\hline TC2 & 0.2 & $\begin{array}{l}\text { Weak traffic: Comfortable and free walking. Overtaking is } \\
\text { possible. Single pedestrians can freely choose pace. }\end{array}$ \\
\hline TC3 & 0.5 & $\begin{array}{l}\text { Dense traffic: Still unrestricted walking. Overtaking can } \\
\text { intermittently be inhibited. }\end{array}$ \\
\hline $\mathrm{TC} 4$ & 1.0 & $\begin{array}{l}\text { Very dense traffic: Freedom of movement is restricted. } \\
\text { Obstructed walking. Overtaking is no longer possible. }\end{array}$ \\
\hline TC5 & 1.5 & $\begin{array}{l}\text { Exceptionally dense traffic: Unpleasant walking. Crowding } \\
\text { begins. One can no longer freely choose pace. }\end{array}$ \\
\hline
\end{tabular}
Footbridges for Human Induced Vibrations (further referred to as JRC document) [32] will be used as a guideline. The JRC document proposes five different typical traffic classes (TC) that can occur on a pedestrian and bicycle bridge, shown in Table 6.

Table 6: Pedestrian traffic classes and densities [32] 
The comfort of the GFRP web-core footbridge will be classified according to four comfort classes (CC) listed in the JRC document, using a limiting value for the vertical acceleration of the bridge as shown in Table 7.

Table 7: Comfort classes with vertical acceleration ranges [32]

\begin{tabular}{ccc}
\hline Comfort class & Degree of comfort & $\begin{array}{c}\text { Vertical acceleration limits, } \\
\mathbf{a}_{\text {lim,vert }}\left[\mathbf{m} / \mathbf{s}^{2}\right]\end{array}$ \\
\hline CC1 & Maximal & $<0.50$ \\
CC2 & Medium & $0.50-1.00$ \\
CC3 & Minimal & $1.00-2.50$ \\
CC4 & Unacceptable discomfort & $>2.50$ \\
\hline
\end{tabular}

The maximum occurring vertical acceleration of the bridge can be calculated by (18).

$$
a_{\text {max }, \text { vert }}=k_{a, 95 \%} \sqrt{\frac{C \cdot \sigma_{F}{ }^{2}}{M_{i}{ }^{2}} \cdot k_{1} \cdot \xi^{k_{2}}}
$$

With [32]:

$k_{a, 95 \%} \quad 95^{\text {th }}$ percentile of the peak factor for the transformation of the standard deviation of the stresses to the characteristic design value of the vertical acceleration in serviceability limit state.

C constant describing the maximum of the load spectrum

$\sigma_{\mathrm{F}}^{2} \quad$ variance of the loading (pedestrian induced forces)

$$
\begin{array}{ll}
\multicolumn{1}{c}{\sigma_{F}^{2}=k_{F} \cdot n} \\
k_{F} & \text { Constant }\left[\mathrm{kN}^{2}\right] \\
n=d_{T C} \cdot L_{b} \cdot B_{\text {use }} & \text { Number of pedestrians on the bridge }
\end{array}
$$

$\mathrm{M}_{\mathrm{i}}{ }^{2} \quad$ modal mass of the considered mode $\mathrm{i}$

$\mathrm{k}_{1}, \mathrm{k}_{2} \quad$ constants depending on the pedestrian density

$$
\begin{aligned}
& k_{1}=a_{1} f_{i}^{2}+a_{2} f_{i}+a_{3} \\
& k_{2}=b_{1} f_{i}^{2}+b_{2} f_{i}+b_{3}
\end{aligned}
$$

$a_{1}, a_{2}, a_{3}, b_{1}, b_{2}, b_{3}$

$\mathrm{f}_{\mathrm{i}}$

constants

considered first natural flexural frequency that coincides with the mean step frequency of the pedestrian stream

$\xi \quad$ structural damping ratio

The value of the structural damping ratio of the bridge depends on many factors, including the construction details, fibre orientations and fibre volume content. The damping of a structure is generally larger than the material damping due to the presence of connections with the environment and in the structure itself. The damping of a laminate or of a construction can be measured with the Dynamic Mechanical Analysis (DMA). The CUR96:2019 [31] gives a minimum value for the damping ratio for a GFRP material of $0.5 \%$ and an average value of $1.0 \%$. However, in practice, the damping ratio of the bridge structure will be larger due to the existing boundary and support conditions. The use of higher damping values than mentioned in the CUR96:2019 [31] and damping values for non-standard materials must be substantiated by representative experimental data. The influence and value of the structural damping ratio $\xi$ will be discussed further on in the parametric study in this paper.

Table 8: Constants for the vertical acceleration with a pedestrian density of less than or equal to $0.5 \mathrm{P} / \mathrm{m}^{2}$

\begin{tabular}{cccccccccc}
\hline $\begin{array}{c}\mathbf{d}_{\mathrm{TC}} \\
{\left[\mathbf{P}_{1} / \mathbf{m}^{2}\right]}\end{array}$ & $\begin{array}{c}\mathbf{k}_{\mathrm{F}} \\
{\left[\mathbf{k N}^{2}\right]}\end{array}$ & $\mathbf{C}$ & $\mathbf{a}_{1}$ & $\mathbf{a}_{2}$ & $\mathbf{a}_{3}$ & $\mathbf{b}_{1}$ & $\mathbf{b}_{2}$ & $\mathbf{b}_{3}$ & $\mathbf{k}_{\mathrm{a}, 95 \%}$ \\
\hline
\end{tabular}




$\begin{array}{llllllllll}\leq 0.5 & 1.20 \times 10^{-2} & 2.95 & -0.070 & 0.600 & 0.075 & 0.003 & -0.040 & -1.000 & 3.92\end{array}$

Figure 3 shows the values $k_{1}$ and $k_{2}$ as a function of the natural frequency and the pedestrian density to determine the vertical acceleration of the bridge deck.
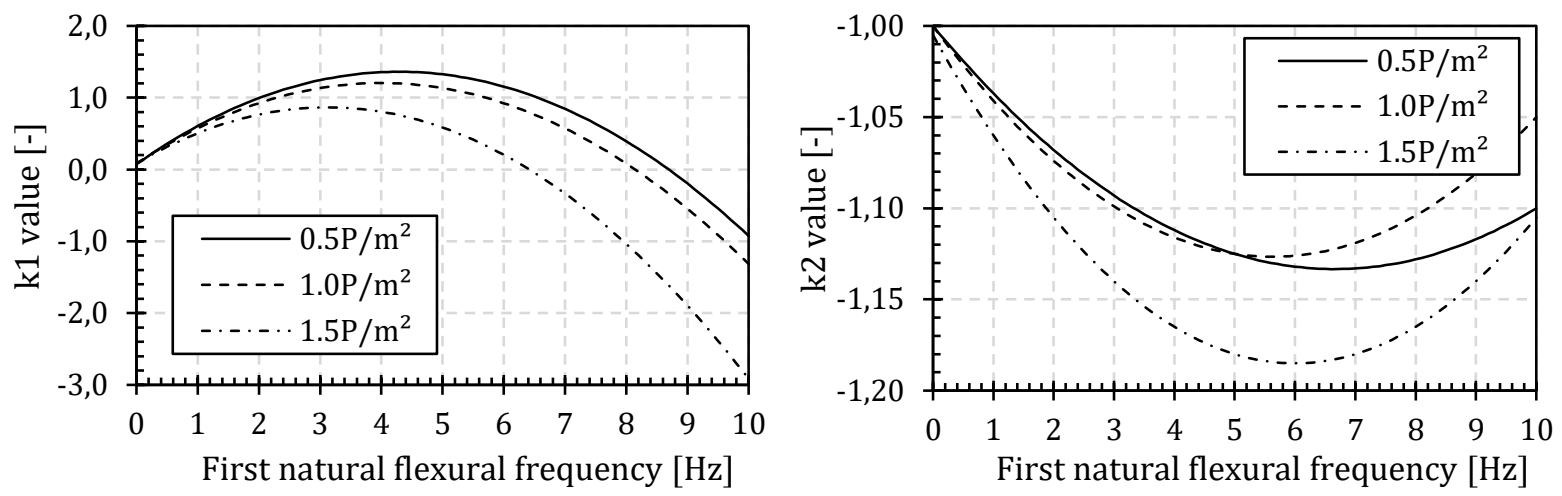

Figure 3: $k_{1}$ and $k_{2}$ values as function of the first natural flexural frequency for different pedestrian traffics

The $\mathrm{k}_{1}$ value for the different pedestrian densities stated in the JRC document will become negative for certain frequencies, which will result in a negative vertical acceleration. However, this is not discussed in the guideline, as the vertical acceleration from a first natural flexural frequency of $4.6 \mathrm{~Hz}$ will be multiplied with a reduction coefficient of 0 , as can be seen in Figure 4 .

The design value of the vertical acceleration of the bridge can be found by multiplying the maximum occurring vertical acceleration with a reduction coefficient $\psi$, which takes into account the probability that the step frequency approaches the critical range of the first natural flexural frequencies of the bridge. Consequently, this reduction coefficient depends on the first natural flexural frequency for a given pedestrian traffic. The value of the reduction coefficient is shown in Figure 4.

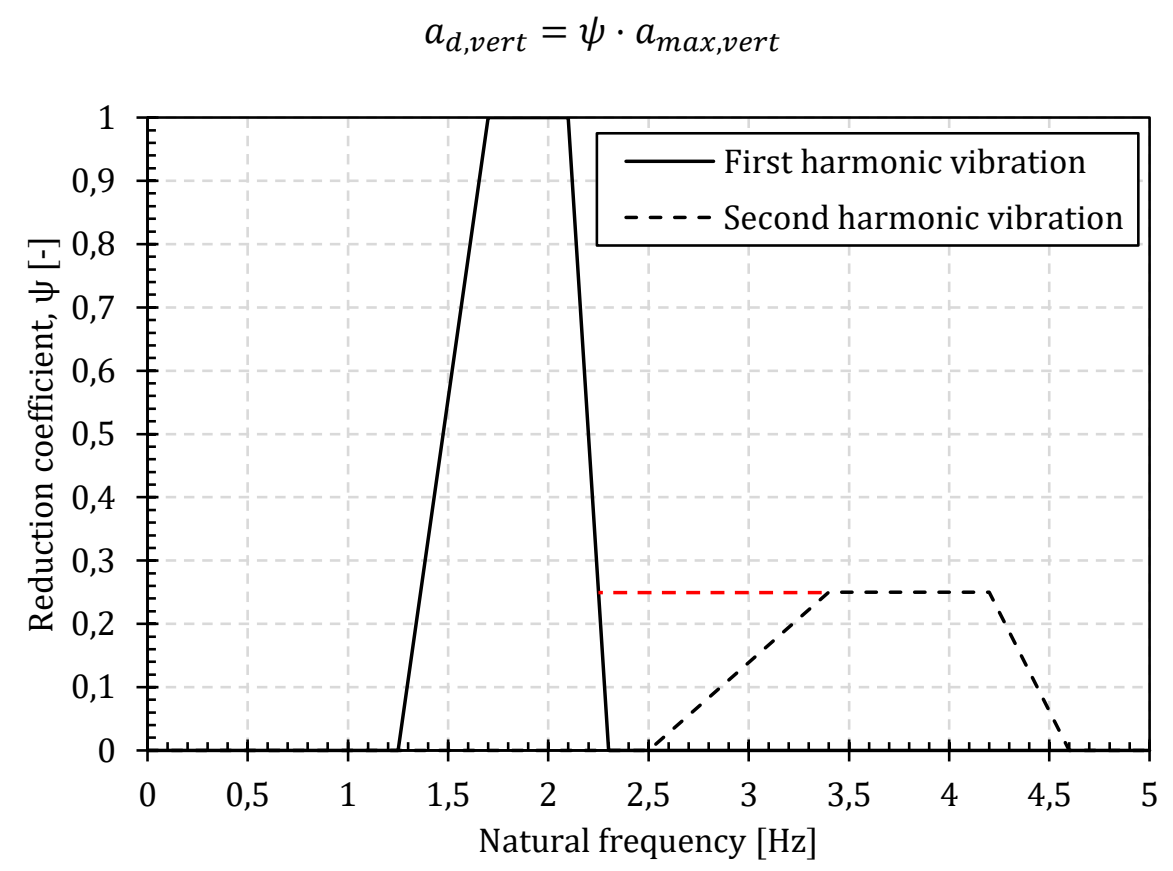

Figure 4: Reduction coefficient for the design vertical acceleration [31] 


\section{Design example}

In this example, a simply supported glass fibre reinforced polymer (GFRP) web-core footbridge, spanning two traffic lanes and adjacent footpaths, will be analytically calculated. The length of the bridge is $16.20 \mathrm{~m}$ with a bridge support length of $0.20 \mathrm{~m}$ on both abutments, resulting in a free span of $16.00 \mathrm{~m}$ according to equation (1). The construction depth of the bridge deck is chosen as $600 \mathrm{~mm}$, giving the bridge a depth to span ratio of about $1 / 27$.

\subsection{Bridge geometry}

The GFRP web-core footbridge has a width of $4.40 \mathrm{~m}$ with a side flange width of $0.20 \mathrm{~m}$ on both sides to anchor the stainless steel handrail, resulting in a useful width of the bridge of $4.00 \mathrm{~m}$. The upper and lower flange both have a thickness of $14 \mathrm{~mm}$ and the interconnecting webs have a thickness of $6 \mathrm{~mm}$ and a centre-to-centre distance of $0.20 \mathrm{~m}$. The edge of the bridge deck is bevelled at an angle of $60^{\circ}$ and has a thickness of $25 \mathrm{~mm}$. Finally, the surfacing on the upper flange over the useful with of the bridge has a thickness of $15 \mathrm{~mm}$, and the design lifespan for the bridge is 100 years as defined by EC1990 [36]. Table 9 provides an overview of the bridge dimensions.

Table 9: Summary bridge dimensions calculation example

\begin{tabular}{ccc}
\hline Discription & Symbol & Value \\
\hline Bridge length & $\mathrm{L}_{\mathrm{b}}$ & $16.20 \mathrm{~m}$ \\
Bridge width & $\mathrm{B}_{\mathrm{b}}$ & $4.40 \mathrm{~m}$ \\
Bridge support length & $\mathrm{L}_{\mathrm{sup}}$ & $0.20 \mathrm{~m}$ \\
Side flange width & $\mathrm{B}_{\mathrm{fl}}$ & $0.20 \mathrm{~m}$ \\
Free span & $\mathrm{L}_{\mathrm{span}}$ & $16.00 \mathrm{~m}$ \\
Useful width & $\mathrm{B}_{\mathrm{use}}$ & $4.00 \mathrm{~m}$ \\
Construction depth & $\mathrm{H}_{\mathrm{b}}$ & $0.60 \mathrm{~m}$ \\
Centre to centre distance of the webs & $\mathrm{CTC}_{\mathrm{w}}$ & $0.20 \mathrm{~m}$ \\
Total surface area & $\mathrm{A}_{\mathrm{b}}$ & $70.40 \mathrm{~m}^{2}$ \\
Useful surface area & $\mathrm{A}_{\mathrm{use}}$ & $64.00 \mathrm{~m}^{2}$ \\
Upper flange thickness & $\mathrm{t}_{\mathrm{uf}}$ & $14 \mathrm{~mm}$ \\
Lower flange thickness & $\mathrm{t}_{\mathrm{lf}}$ & $14 \mathrm{~mm}$ \\
Web plate thickness & $\mathrm{t}_{\mathrm{w}}$ & $6 \mathrm{~mm}$ \\
Edge thickness & $\mathrm{t}_{\mathrm{e}}$ & $25 \mathrm{~mm}$ \\
Surfacing thickness & $\mathrm{t}_{\mathrm{s}}$ & $15 \mathrm{~mm}$ \\
\hline
\end{tabular}

The characteristic values for the stiffnesses and the Poisson ratio of a single UD layer consisting of E-glass fibres and polyester resin can be found in Table 10.

Table 10: Characteristic values of a single UD E-glass/polyester composite layer

\begin{tabular}{lll}
\hline Materials & \multicolumn{2}{l}{ E-Glass/Polyester } \\
Fibre volume percentage & $\mathrm{V}_{\mathrm{f}}$ & $55 \%$ \\
Longitudinal stiffness & $\mathrm{E}_{1}$ & $40500 \mathrm{MPa}$ \\
Transverse stiffness & $\mathrm{E}_{2}$ & $12900 \mathrm{MPa}$ \\
Shear stiffness & $\mathrm{G}_{12}$ & $2900 \mathrm{MPa}$ \\
Poisson ratio & $\mathrm{V}_{12}$ & 0.30 \\
\hline
\end{tabular}

The composition of the various laminates in the bridge is shown in Table 11 by means of the percentage of the thickness taken up by each of the four main directions. The specific structure of the laminates and the positioning of the layers relative to the neutral axis of the laminate will be taken into account. 
Table 11: Construction of the various laminates in the bridge

\begin{tabular}{|c|c|c|c|c|c|}
\hline & \multirow{2}{*}{$\begin{array}{c}\text { Laminate } \\
\text { thickness } \\
{[\mathrm{mm}]}\end{array}$} & \multicolumn{4}{|c|}{ Percentage of thickness for each fibre direction [\%] } \\
\hline & & $\mathbf{0}^{\circ}$ & $90^{\circ}$ & $45^{\circ}$ & $-45^{\circ}$ \\
\hline Upper flange & 14 & 50 & 10 & 20 & 20 \\
\hline Lower flange & 14 & 50 & 10 & 20 & 20 \\
\hline Web plate & 6 & 0 & 50 & 25 & 25 \\
\hline Edge & 25 & 0 & 50 & 25 & 25 \\
\hline
\end{tabular}

A summary of the equivalent stiffness and strength of the different laminates in the bridge can be found in Table 12.

Table 12: Equivalent stiffness and strength for the laminates in the bridge

\begin{tabular}{ccccccc}
\hline & $\begin{array}{c}\mathbf{E}_{\mathbf{x}} \\
\text { [GPa] }\end{array}$ & $\begin{array}{c}\mathbf{E}_{\mathbf{y}} \\
\text { [GPa] }\end{array}$ & $\begin{array}{c}\mathbf{G}_{\mathbf{x y}} \\
\text { [GPa] }\end{array}$ & $\begin{array}{c}\mathbf{f}_{\mathbf{x t}, \mathbf{R k}}, \mathbf{f}_{\mathbf{x c}, \mathbf{R k}} \\
{[\mathbf{M P a}]}\end{array}$ & $\begin{array}{c}\mathbf{f}_{\mathbf{y t}, \mathbf{R k}}, \mathbf{f}_{\mathbf{y c}, \mathbf{R k}} \\
{[\mathbf{M P a}]}\end{array}$ & $\begin{array}{c}\mathbf{\tau}_{\mathbf{x y}, \mathbf{R k}} \\
{[\mathbf{M P a}]}\end{array}$ \\
\hline Upper flange & 26.57 & 16.36 & 6.46 & 318.87 & 196.35 & 103.31 \\
Lower flange & 26.57 & 16.36 & 6.46 & 318.87 & 196.35 & 103.31 \\
Web plate & 13.62 & 25.79 & 7.34 & 163.49 & 309.44 & 117.14 \\
Edge & 13.62 & 25.79 & 7.34 & 163.49 & 309.44 & 117.14 \\
\hline
\end{tabular}

The longitudinal bending stiffness $\mathrm{EI}_{\mathrm{x}}$ and the shear stiffness $\mathrm{GA}_{\mathrm{xy}}$ can be determined for the crosssection of the bridge based on the laminate stiffnesses mentioned in Table 12 and the geometry of the bridge shown in Figure 2. The bending stiffness $\mathrm{EI}_{\mathrm{x}}$ and the shear stiffness $\mathrm{GA}_{\mathrm{xy}}$ are 438.63 $\mathrm{MNm}^{2}$ and $721.03 \mathrm{MN}$ respectively.

Table 13: Permanent loads on GFRP pedestrian and bicycle bridge

\begin{tabular}{cc}
\hline Description & Mass [kg] \\
\hline Mass bridge structure, $\mathrm{m}_{\text {struc }}$ & 8757 \\
${\text { Mass surfacing, } \mathrm{m}_{\text {surf }}}^{\text {Mass handrail, } \mathrm{m}_{\mathrm{hr}}}$ & 1652 \\
Total permanent mass, $\mathbf{m}_{\text {tot }}$ & $\mathbf{1 0 7 3 3}$ \\
\hline
\end{tabular}

The permanent mass of the bridge will be converted to a uniformly distributed load over the total surface area of the bridge.

$$
q_{S W}=\frac{m_{t o t} \cdot g}{A_{b}}=1,48 \mathrm{kN} / \mathrm{m}^{2}
$$

\subsection{Ultimate limit state (ULS)}

The flexural moments required to check the strength of the upper and lower flanges in the ULS, respectively under the self-weight, the distributed load, the service vehicle and the unintended vehicle are:

$$
M_{S W}=208.00 \mathrm{kNm} \quad M_{q}=588.47 \mathrm{kNm} \quad M_{s v}=200.00 \mathrm{kNm} \quad M_{u v}=480.00 \mathrm{kNm}
$$

The determining load combination can then be obtained from load combinations 3, 4 and 6 .

$$
\begin{gathered}
M_{L C 3}=1771.18 \mathrm{kNm} \quad M_{L C 4}=994.24 \mathrm{kNm} \quad M_{L C 6}=1554.24 \mathrm{kNm} \\
M_{\max }=1771.18 \mathrm{kNm}
\end{gathered}
$$

The distance from the top of the upper $\left(\mathrm{y}_{\mathrm{h} 0}\right)$ and bottom of the lower $\left(\mathrm{y}_{\mathrm{h} 1}\right)$ flange of the bridge deck to the neutral axis is in both cases $300 \mathrm{~mm}$, from which the moment of inertia of the flanges can be calculated: $I_{x, f}=96.90 \cdot 10^{8} \mathrm{~mm}^{4}$. 
The longitudinal maximum occurring bending stresses in the upper and lower fibre will therefore be equal to: $\sigma_{x, u f, M}=\sigma_{x, l f, M}=54.84 M P a$.

Unity check for the strength of the upper and lower flanges in respectively compression and tension in the longitudinal direction:

$$
u c_{\sigma_{x, u f, M}}=0.17 \leq 1 \quad u c_{\sigma_{x, l f, M}}=0.17 \leq 1
$$

As mentioned in section 2.5.1, these unity checks are well below 1 . This is remarkable, certainly when considering the combination of various partial material and conversion factors used in expression (12). As will be shown further in this paper, these results are very common for webcore sandwich panel FRP composite footbridges, which are dominated by SLS rather than ULS design.

The shear forces in the webs to check the strength of the web plates in the ULS under self-weight, distributed load, service vehicle and unintended vehicle are:

$$
V_{S W}=2.36 \mathrm{kN} \quad V_{q}=7.97 \mathrm{kN} \quad V_{s v}=11.61 \mathrm{kN} \quad V_{u v}=28.80 \mathrm{kN}
$$

The determining load combination can then be obtained from load combinations 3, 4 and 6 .

$$
\begin{array}{cl}
V_{L C 3}=22.69 k N & V_{L C 6}=64.975 k N \\
V_{\text {max }} & =64.35 k N
\end{array}
$$

The cross-sectional area of one web plate is: $A_{w}=3432.00 \mathrm{~mm}^{2}$, from which the shear stresses in the webs can be calculated: $\tau_{x y, w, V}=18.75 \mathrm{MPa}$.

Unity check for the strength of the webs in shear:

$$
u c_{\tau_{x y, w, V}}=0.16 \leq 1
$$

In addition, the web plates will also be checked against the compression that takes place in one web. The load is $P_{L C 5}=100.30 \mathrm{kN} / \mathrm{m}$, from which the stress in one web plate under compression can be calculated: $\sigma_{y, w, L C 5}=33.43 \mathrm{MPa}$.

Unity check for the strength of the webs in compression:

$$
u c_{\sigma_{y, w, L C 5}}=0.11 \leq 1
$$

Yet again, as mentioned in section 2.5.2, the unity checks are well below 1, proving once more that web-core sandwich panel FRP composite footbridges are dominated by SLS rather than ULS design.

\subsection{Serviceability limit state (SLS)}

In SLS, a deflection limit criterion of $1 / 250$ is imposed, resulting in a maximum tolerable deflection of the bridge at midspan of $64.80 \mathrm{~mm}$. The long-term deflection under load combination 3 for the uniformly distributed load and load combination 4 for the service vehicle are $w_{L C 3}=45.18 \mathrm{~mm}$ and $w_{L C 4}=11.59 \mathrm{~mm}$ respectively.

Unity check for the deflection of the bridge at midspan:

$$
u c_{L C 3}=0.70 \quad u c_{L C 4}=0.18
$$

In this example, the SLS deflection criterion is the governing criterion in the preliminary design. 
The SLS verification will also determine the natural frequency of the bridge and, based on this, the comfort level of the bridge. Table 14 gives a summary of the first natural flexural frequency $\left(\mathrm{f}_{0}\right)$ in unloaded and loaded condition for different traffic classes together with the unity checks against the relevant criterion (uc).

Table 14: First natural flexural frequency for five traffic classes

\begin{tabular}{cccccc}
\hline $\begin{array}{c}\text { Traffic } \\
\text { class }\end{array}$ & $\begin{array}{c}\mathbf{d}_{\text {TC }} \\
{\left[\mathbf{P}_{\mathbf{1}} / \mathbf{m}^{\mathbf{2}} \mathbf{]}\right.}\end{array}$ & $\begin{array}{c}\mathbf{f}_{\mathbf{0}, \text { load }} \\
{[\mathbf{H z}]}\end{array}$ & $\begin{array}{c}\mathbf{u c}_{\mathbf{f} 0, \text { load }} \\
{[-]}\end{array}$ & $\begin{array}{c}\mathbf{f}_{\mathbf{0}, \text { unload }} \\
{[\mathbf{H z}]}\end{array}$ & $\begin{array}{c}\mathbf{u c}_{\mathbf{f o}, \text { unload }} \\
{[-]}\end{array}$ \\
\hline TC1 & 0.1 & 4.39 & 0.51 & & \\
TC2 & 0.2 & 4.29 & 0.52 & & \\
TC3 & 0.5 & 4.03 & 0.56 & 4.49 & 0.67 \\
TC4 & 1.0 & 3.68 & 0.61 & & \\
TC5 & 1.5 & 3.41 & 0.66 & & \\
\hline
\end{tabular}

Table 15 shows the comfort classes of the bridge for the different pedestrian traffic classes, calculated with a structural damping ratio of 0.5 and 1.0\% as stated in the guideline CUR96:2019 [31].

Table 15: Results for vertical acceleration and comfort class with a structural damping ratio of $0.5 \%$ and $1.0 \%$ for different traffic classes

\begin{tabular}{|c|c|c|c|}
\hline $\begin{array}{c}\text { Traffic } \\
\text { class }\end{array}$ & $\begin{array}{c}\mathbf{d}_{\mathrm{TC}} \\
{\left[\mathbf{P}_{\mathbf{1}} / \mathbf{m}^{2}\right]}\end{array}$ & $\begin{array}{c}\mathbf{a}_{\mathrm{d}, \text { vert, }, .5 \%} \\
{\left[\mathrm{~m} / \mathrm{s}^{2}\right]}\end{array}$ & $\begin{array}{c}\mathbf{a}_{\mathbf{d}, \mathrm{vert}, \mathbf{1 . 0} \%}\left[\mathrm{~m} / \mathbf{s}^{2}\right] \\
\end{array}$ \\
\hline TC1 & 0.1 & 0.84 (CC2) & 0.57 (CC2) \\
\hline TC2 & 0.2 & 1.74 (СС3) & $1.18(\mathrm{CC} 3)$ \\
\hline TC3 & 0.5 & 4.34 (CC4) & 2.95 (CC4) \\
\hline TC4 & 1.0 & 4.77 (CC4) & 3.24 (CC4) \\
\hline TC5 & 1.5 & 4.41 (CC4) & 2.96 (CC4) \\
\hline
\end{tabular}

As a preliminary conclusion, the predetermined requirements for the deflection $(\mathrm{L} / 250)$ and the natural frequency in unloaded and loaded condition (respectively $3.00 \mathrm{~Hz}$ and $2.25 \mathrm{~Hz}$ ) can be met with reasonable dimensions for the construction depth and the thickness of the flanges and webs for a GFRP web-core footbridge with a span of $16 \mathrm{~m}$. Furthermore, the strength of the upper and lower flange and webs will typically not pose a problem in the design of a GFRP web-core footbridge, as barely $20 \%$ of the capacity will be used. However, with the current dimensions of the bridge, it will be impossible to meet the comfort requirements for the majority of the traffic classes with the predetermined values of the damping ratio from CUR96:2019. An increase in damping ratio of $0.5 \%$ to $1.0 \%$ will cause a $32 \%$ reduction in the design vertical acceleration. The influence of the damping ratio on the design of the GFRP web-core footbridge will be studied in the subsequent parametric study.

\section{Discussion and parametric study}

In the first part of the discussion, the calculation example will be addressed further. The basic data (materials, loads, geometry) will be maintained, especially the span of $16 \mathrm{~m}$, except for the flange thickness and slenderness. This will allow visualising the unity checks for varying slendernesses as well as the influence of the SLS requirements and the damping ratio, for a given span.

In the second part, the discussion will be extended to other spans (6-24 m), focussing on unity checks, influence of SLS requirements and damping ratio.

In the final part, the influence of the bridge width, the addition of non-structural elements, the boundary conditions, the traffic class and the use of other materials will be addressed.

Given the possible confusion as to the definition of slenderness as span to depth or depth to span ratio, in what follows the term depth to span ratio is used (e.g. $1 / 20 ; 0,05)$ throughout. 


\subsection{Constant bridge span}

\subsubsection{Unity checks and structural mass as a function of the depth to span ratio}

In the calculation example, the bridge was analysed on the basis of predetermined values for the construction depth and thicknesses of the different laminates. However, it will be possible to calculate the bridge with different parameters due to the interaction between the construction depth and the thickness of the laminates. The thicknesses of the upper and lower flanges are kept equal to each other, with minimum and maximum values of 8 and $50 \mathrm{~mm}$ respectively, and the webs are consistently half that thickness. The thickness of the laminates is increased in steps of $0.0168 \mathrm{~mm}$ from the minimum value of $8 \mathrm{~mm}$ until all unity checks are met, or until the limit of 50 $\mathrm{mm}$ is reached at 2500 steps. The results are shown in Figure 5, where the depth to span ratio of the bridge of $16.2 \mathrm{~m}$ is varied over an interval of $1 / 100$ to $1 / 14$.

The design is done on the basis of a deflection requirement of $\mathrm{L} / 250$, a pedestrian traffic class of $0.5 \mathrm{P} / \mathrm{m}^{2}$ and, in contrast to the design example, the comfort must comply to comfort class 2 (medium comfort) with a maximum vertical acceleration of $1.0 \mathrm{~m} / \mathrm{s}^{2}$ and a value of $0.5 \%$ for the structural damping ratio.

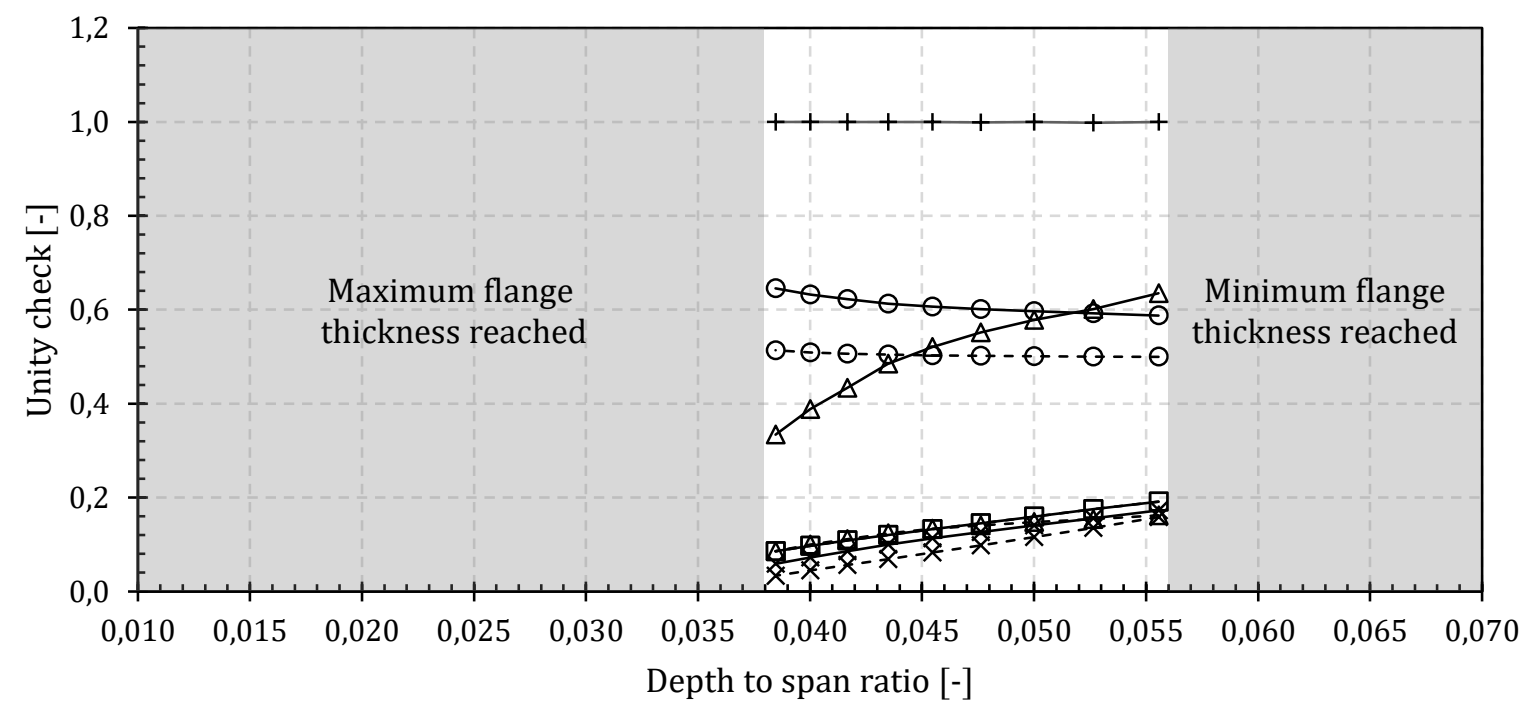

\begin{tabular}{|c|c|}
\hline$\triangle \triangle$ UC deflection LC3 & $--\Delta^{-}-$UC deflection LC4 \\
\hline - & - - ๑- - UC natural frequency loaded \\
\hline$\square$ UC stresses upper flange & - - 曰- UC stresses bottom flange \\
\hline$\longrightarrow$ UC shear stresses webs & - - X- - UC compression webs \\
\hline+ UC vertical acceleration & \\
\hline
\end{tabular}

Figure 5: Evolution of the unity checks and limiting values as a function of the depth to span ratio of the calculation example with a bridge span of $16 \mathrm{~m}(\mathrm{~L} / 250, \mathrm{TC} 3, \mathrm{CC} 2,0.5 \%)$

In the graph, three areas can be distinguished, which are delimited by two limit values. In the first area, from a depth to span ratio of $0.010(1 / 100)$ to the left hand side limit value of $0.025(1 / 40)$, not all unity checks can be met if the maximum laminate thickness is respected. In the third area, from the right hand side limit value of $0.055(1 / 18)$ to $0.070(1 / 14)$, the minimum thickness of the upper flange is reached. Decreasing the thickness further would lead to a lack of resistance to local force introduction, whereas keeping the thickness constant at $8 \mathrm{~mm}$ would cause all unity checks to be significantly below one. The second area, located in the middle, displays all possible construction depth configurations complying to all unity checks. From Figure 5, it is clear that the dominant criterion for the design of the bridge is the vertical acceleration. 
The following graphs show the structural mass per square meter for different deflection requirements and comfort class CC2 in Figure 6, and without applying a comfort requirement (which is equivalent to CC4) in Figure 7.

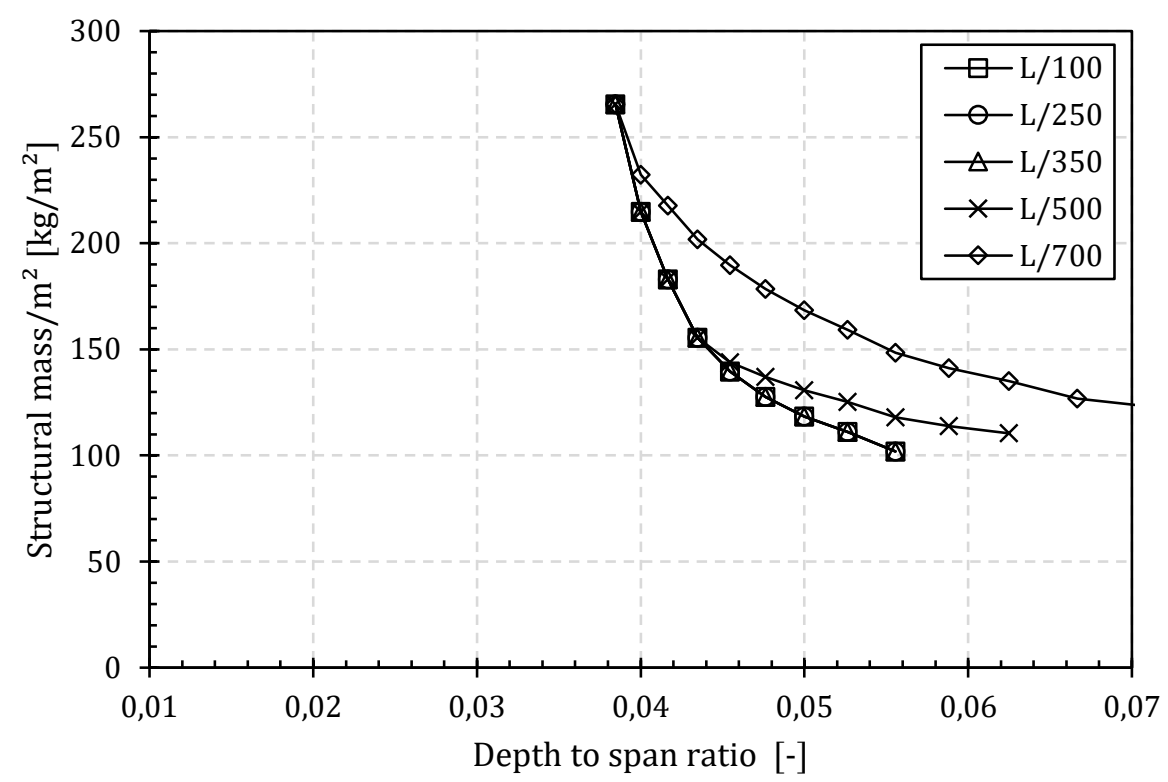

Figure 6: Structural mass per square meter for various deflection criteria and a medium comfort requirement (TC3, CC2, 0.5\%)

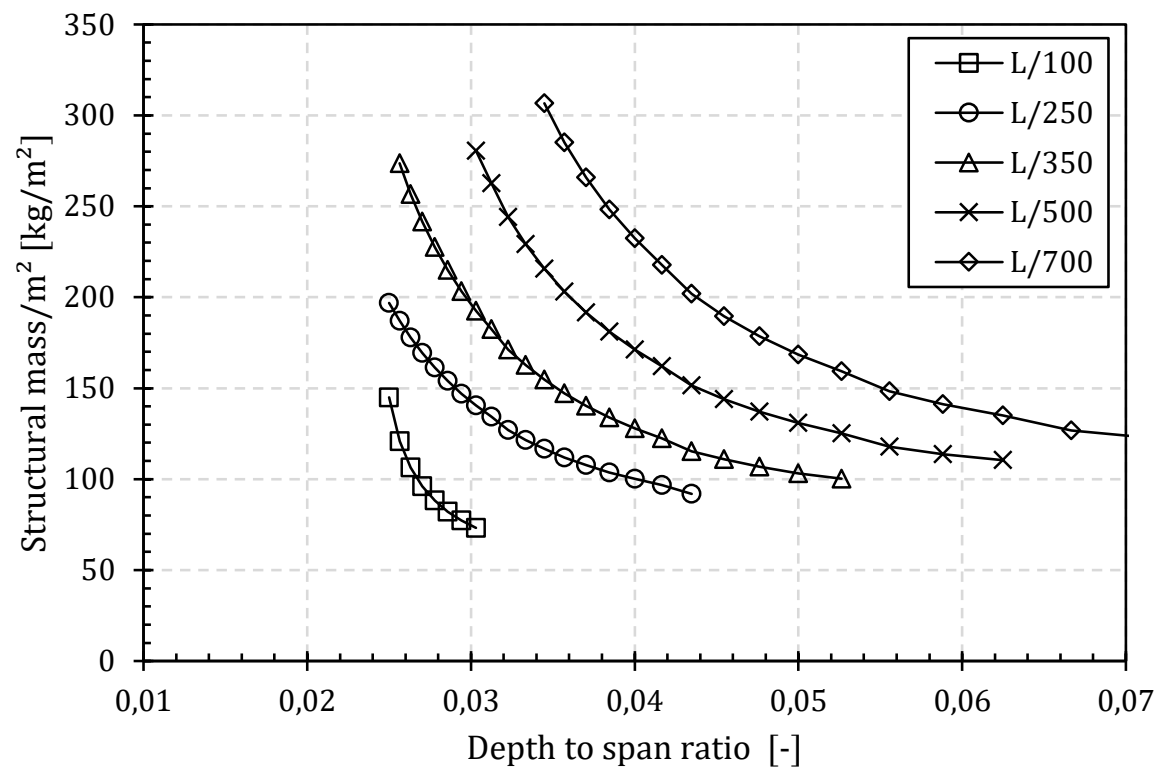

Figure 7: Structural mass per square meter for various deflection criteria and without a comfort requirement (TC3, CC4, 0.5\%)

From Figure 6 and Figure 7, it can be deduced that the CC2 comfort requirement fully determines the design of a $16 \mathrm{~m}$ GFRP web-core footbridge, no matter whether a deflection requirement of $\mathrm{L} / 100, \mathrm{~L} / 250$ or L/350 was imposed. Only for the excessive deflection requirements $\mathrm{L} / 500$ and $\mathrm{L} / 700$ and for depth to span ratios smaller than $0.043(1 / 23)$ and $0.035(1 / 26)$ respectively, the design of the bridge would be determined by the deflection. For a medium span footbridge, the comfort criterion is clearly decisive.

Should however no comfort criterion be imposed, it is clear that the limiting value for the live load deformation is decisive for the material consumption. For a common depth to span ratio of 0,03 
(1/33), structural masses of $70 \mathrm{~kg} / \mathrm{m}^{2}(\mathrm{~L} / 100), 140 \mathrm{~kg} / \mathrm{m}^{2}$ (L/250), and $190 \mathrm{~kg} / \mathrm{m}^{2}(\mathrm{~L} / 350)$ are found. Note that when CC2 is required, this depth to span ratio is not even achievable (Fig. 6).

\subsubsection{Influence of the comfort criterion}

The influence of the proposed comfort requirement for the design of the bridge according to the JRC document is shown in Figure 8 for the GFRP web-core footbridge of the design example with a span of $16 \mathrm{~m}$ and for different structural damping ratios. For comfort requirement CC4, no limiting value for the vertical acceleration is set, and the design is in this case mainly dominated by the unity checks for the deflection under the distributed load (LC3) and the natural frequency in unloaded state.
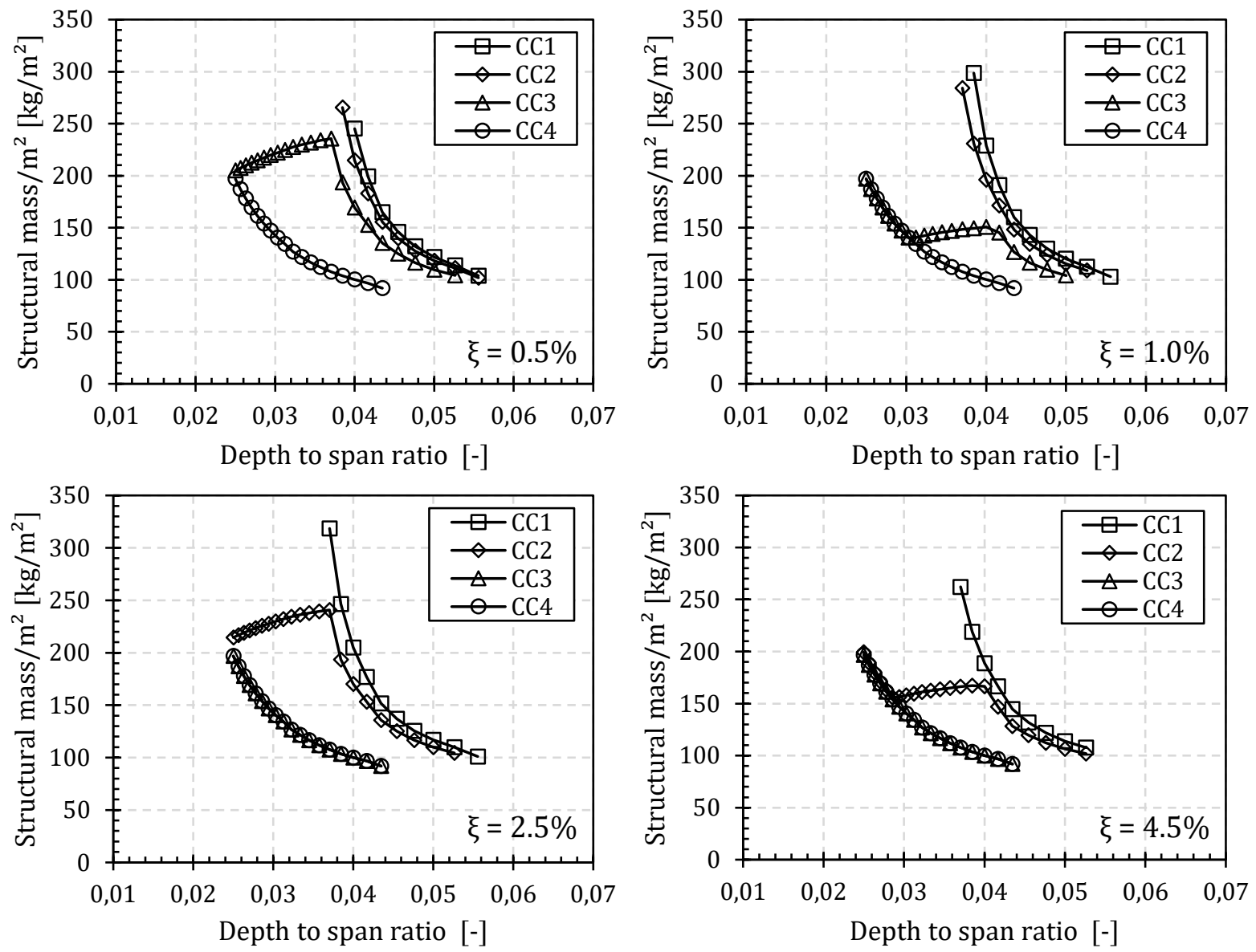

Figure 8: Structural mass per square meter as a function of the depth to span ratio and the comfort criterion for a bridge span of $16 \mathrm{~m}$ and different damping ratios $(\mathrm{L} / 250, \mathrm{TC} 3)$

An easing of the comfort requirement will lead to the design of slimmer and lighter bridges with thinner flanges and web plates. For example, for a depth to span ratio of $0.04(1 / 25)$, the structural mass of the bridge for CC2 and $\xi=0.5 \%$ will be $215 \mathrm{~kg} / \mathrm{m}^{2}$. For CC1, the structural mass will increase with $14 \%$ to $245 \mathrm{~kg} / \mathrm{m}^{2}$. Contrarily, for the comfort requirements CC3 and CC4, lighter bridges with a structural mass of 169 and $100 \mathrm{~kg} / \mathrm{m}^{2}$ respectively, are obtained, leading to a reduction of 21 and 53\%. In addition, it will be possible to obtain a slimmer bridge with the same structural mass if the comfort requirements are relaxed.

For depth to span ratios smaller than 0.037 (1/27), a comfort requirement CC3 and a structural damping ratio of $0.5 \%$, the first natural flexural frequency of the bridge in loaded condition will be larger than $4.2 \mathrm{~Hz}$ (Figure 9 left), resulting in a reduction coefficient smaller than 0.25 for the calculation of the vertical acceleration as shown in Figure 4. Consequently, the required thicknesses of the upper and lower flange (Figure 9 right) and of the webs in order to achieve the predefined comfort class increase to a lesser extent. As a result, the unity check for the deflection 
under a uniformly distributed load for depth to span ratios smaller than 0.037 (1/27) will increase (Figure 10) and the structural mass of the bridge will decrease.
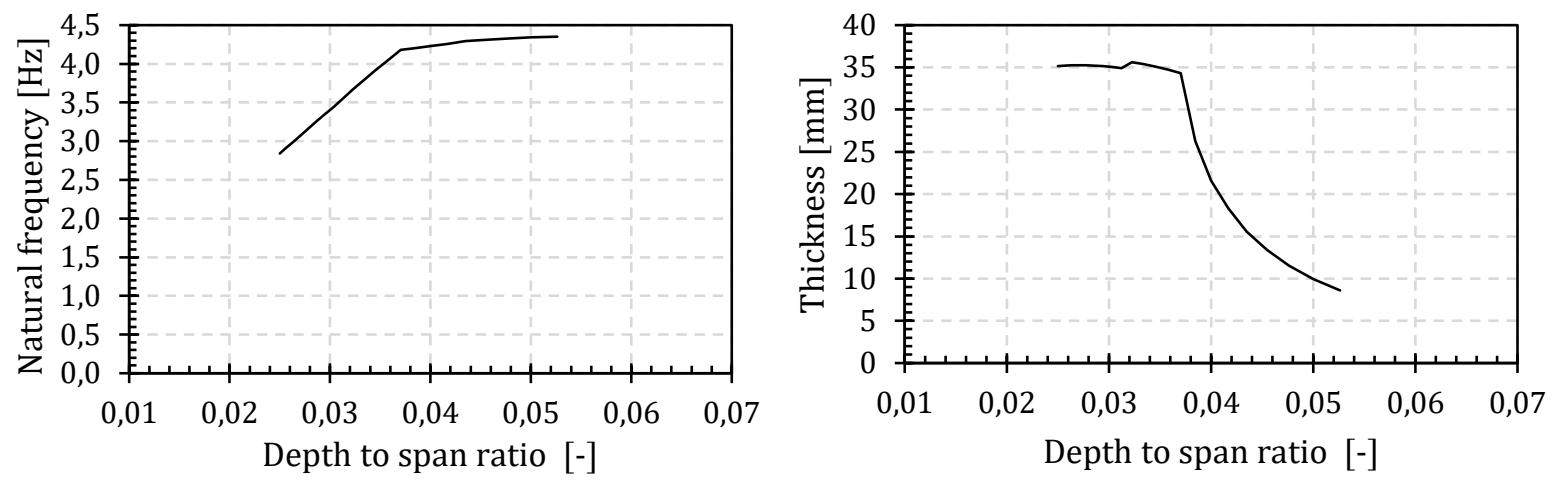

Figure 9: Evolution of the first natural flexural frequency in loaded condition (left) and thickness of the upper flange (right) for a bridge span of $16 \mathrm{~m}$ and CC3

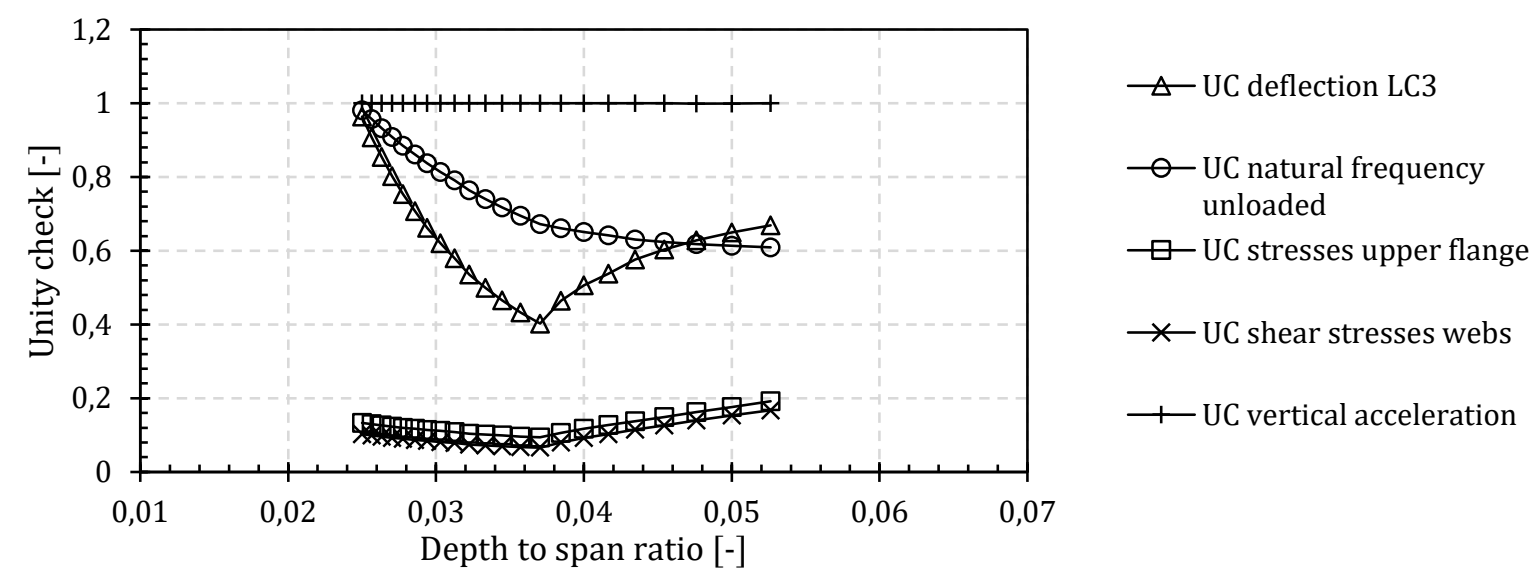

Figure 10: Unity checks for a bridge span of $16 \mathrm{~m}$ and CC3

\subsubsection{Influence of the damping ratio}

Similarly, the influence of the structural damping ratio in the design of the GFRP web-core footbridge is considered in Figure 11. The assessment is based on a deflection requirement of $\mathrm{L} / 250$, traffic class 3 , comfort class 2 and a varying damping ratio with a value of $0.5 \%, 1.0 \%, 2.5 \%$ and $4.5 \%$. As for the comfort requirement, the increase in the structural damping ratio in the calculation of the bridge will result in a reduction in the structural mass and will make it possible to design a more slender bridge.

For depth to span ratios less than $0.04(1 / 25)$ and a damping ratio of $4.5 \%$, the first natural flexural frequency of the bridge in loaded condition will be larger than $4.2 \mathrm{~Hz}$, making the reduction coefficient for the calculation of the design vertical acceleration smaller than 0.25 . This results in smaller flange thicknesses and a reduction of the structural mass. For depth to span ratios smaller than $0.029(1 / 35)$, the unity check for the deflection will become dominant again with a significant increase in the thickness of the flanges and therefore an increase in the structural mass of the bridge (Figure 12). 


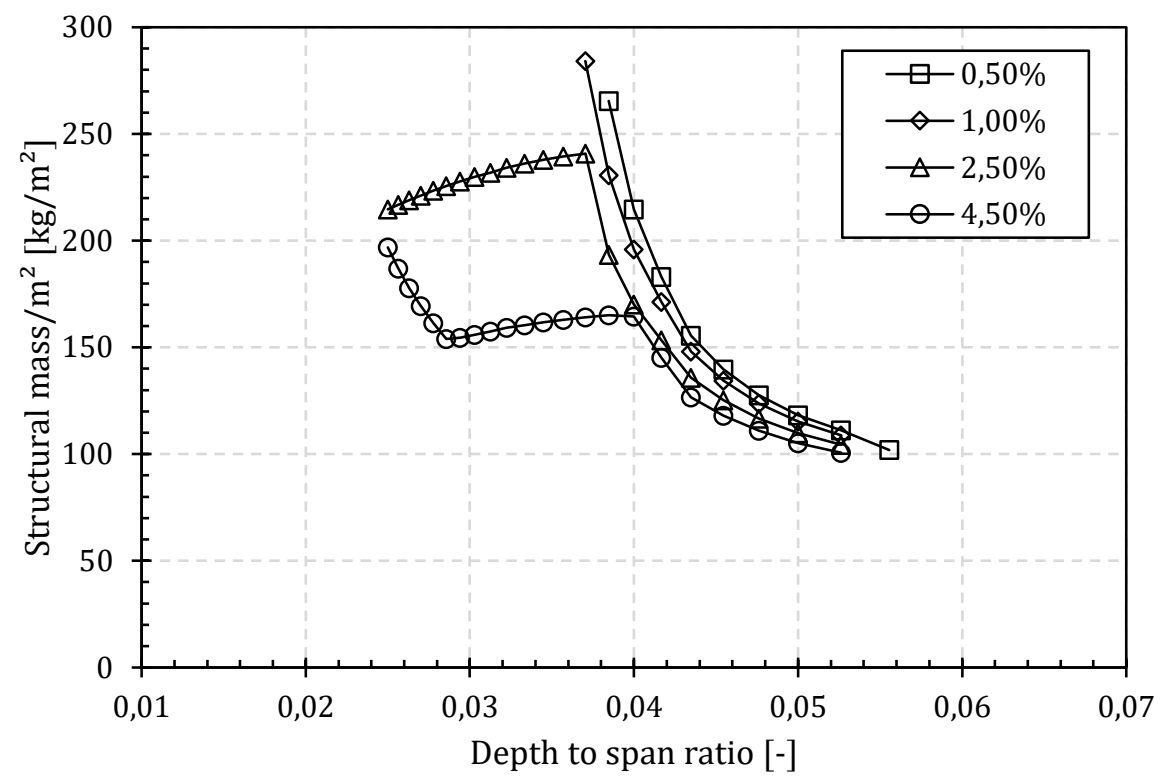

Figure 11: Structural mass per square meter as a function of the depth to span ratio and the structural damping ratio for a bridge span of $16 \mathrm{~m}(\mathrm{~L} / 250, \mathrm{TC} 3, \mathrm{CC} 2)$

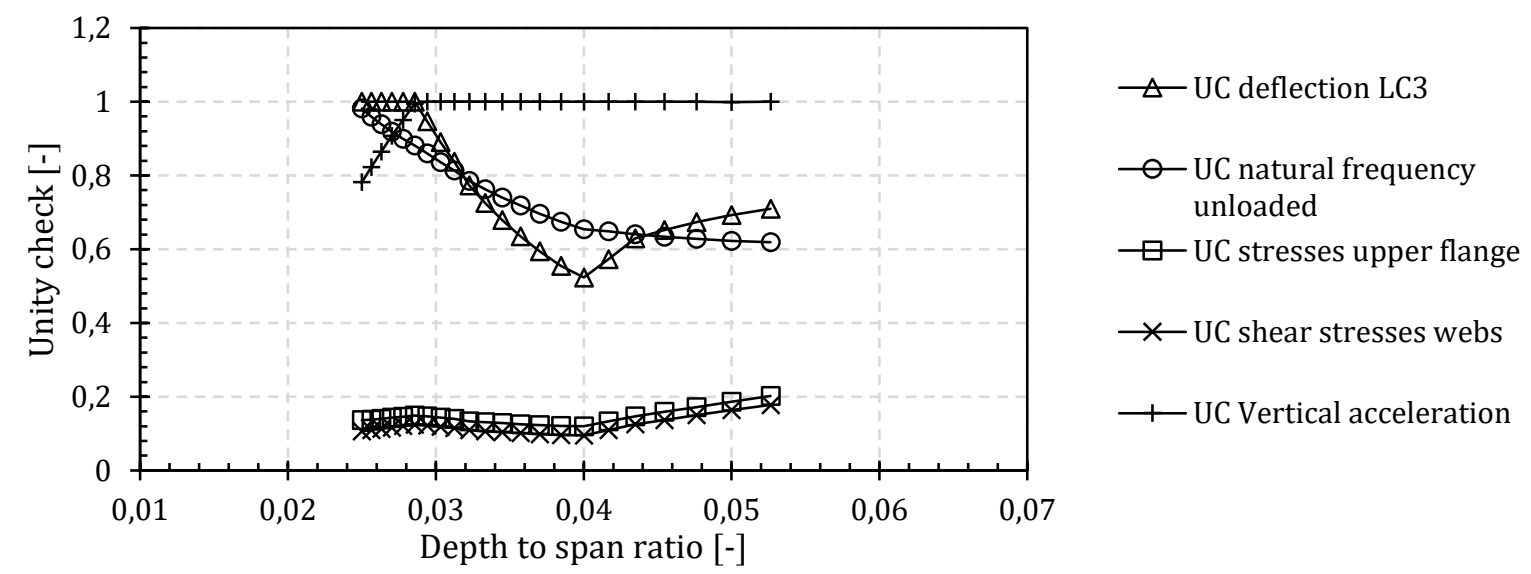

Figure 12: Unity checks for a bridge span of $16 \mathrm{~m}$ and a damping ratio of $4.5 \%$

In the next paragraph, the findings related to unity checks, influence of the SLS requirements and damping ratio will be further explored for smaller and larger spans.

\subsection{Variable bridge span}

In this section, the unity checks, structural mass per square meter and the first natural flexural frequency will first be shown as a function of the depth to span ratio for various bridge spans. Afterwards, the influence of the comfort criterion, the damping ratio, the useful width, the addition of non-structural mass by the surfacing and the handrail, the boundary conditions and the volume of the pedestrian traffic in the design of the bridge will be examined.

\subsubsection{Unity checks and structural mass as a function of the depth to span ratio}

Figure 13 shows the evolution of the unity checks and limiting values for four different spans of a GFRP web-core footbridge. The design is done with a deflection requirement of $\mathrm{L} / 250$, traffic class 3 , comfort class 2 and a damping ratio of $0.5 \%$. 


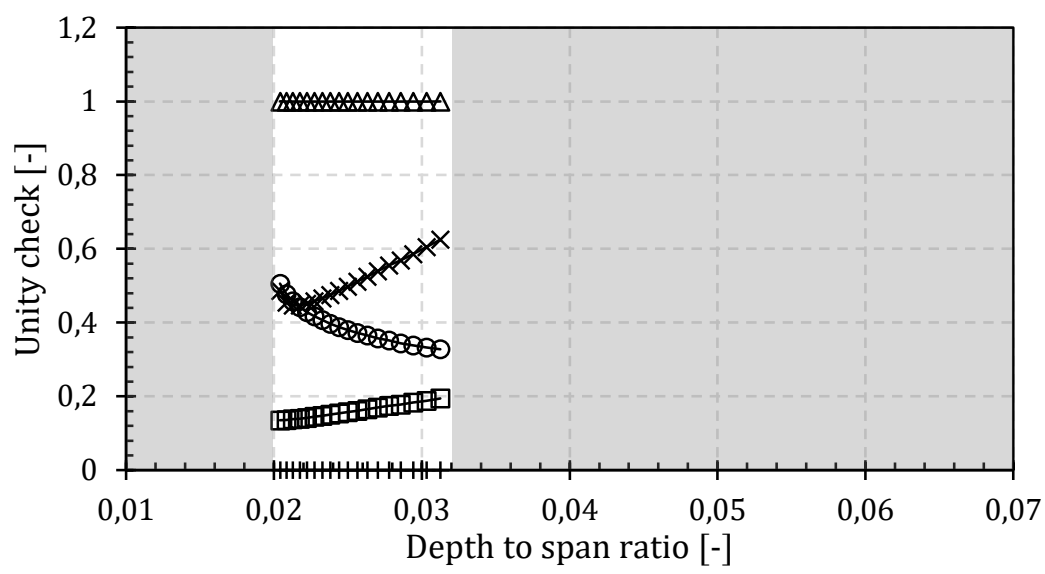

\section{$6 \mathrm{~m}$}

$\triangle$ Deflection LC3

- - First natural flexural frequency unloaded

$\square$ Stresses upper flange

$\leftarrow$ Shear stresses webs

— Vertical accelerations

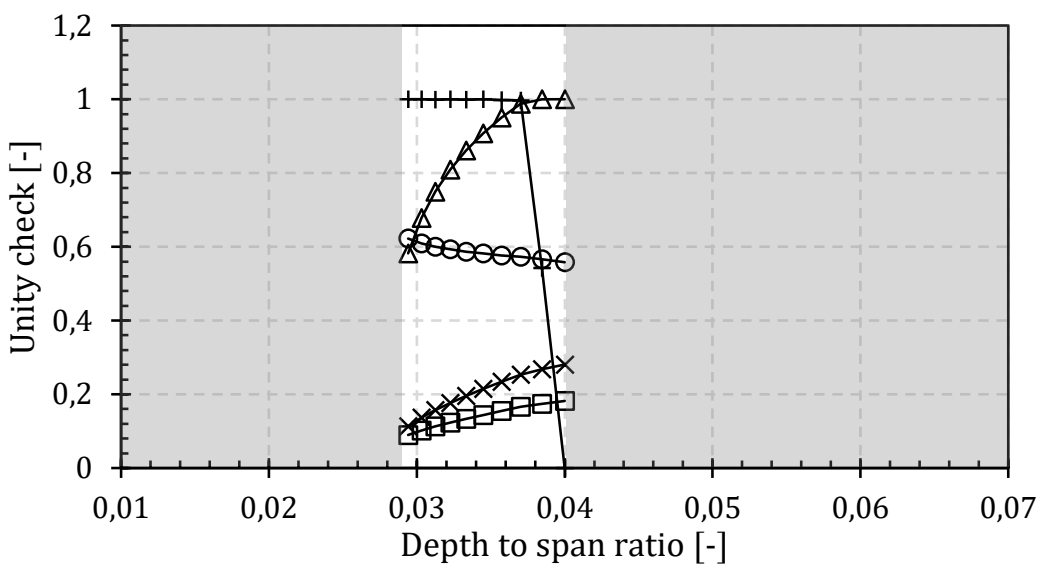

$12 \mathrm{~m}$

$\triangle$ Deflection LC3

- First natural flexural frequency unloaded

$\square$ - Stresses upper flange

$\leftarrow$ Shear stresses webs

$\_$Vertical accelerations

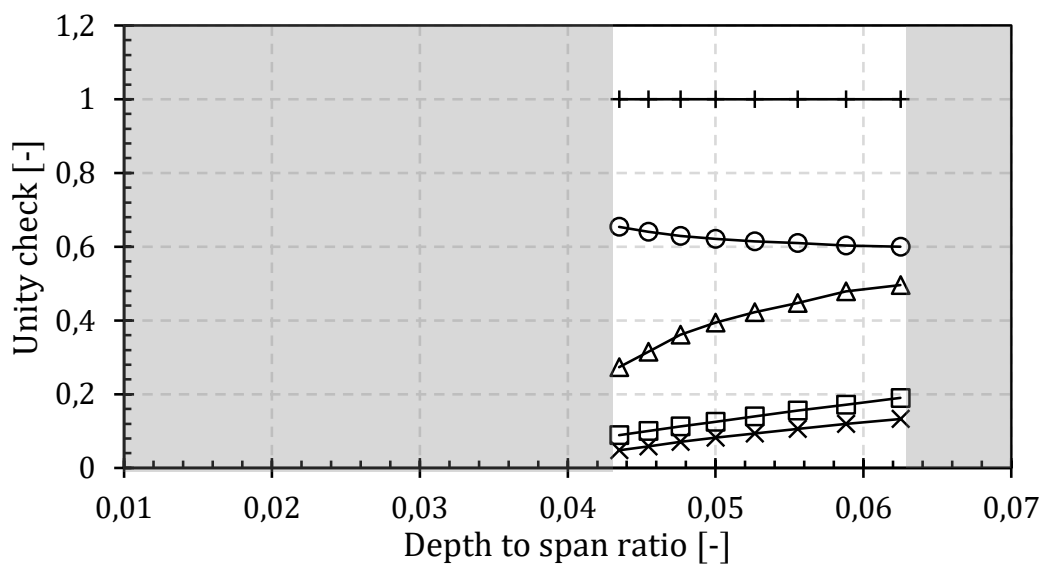

$18 \mathrm{~m}$

$\triangle$ Deflection LC3

— First natural flexural frequency unloaded

$\square$ Stresses upper flange

$\leftarrow$ Shear stresses webs

— Vertical accelerations

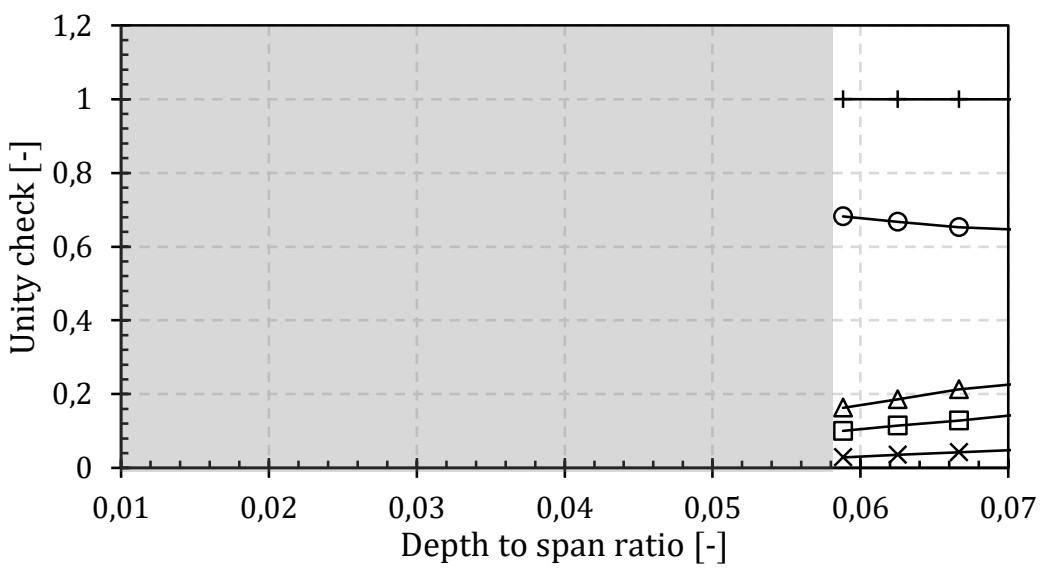

$24 \mathrm{~m}$

$\triangle$ Deflection LC3

○- First natural flexural frequency unloaded

$\square$ Stresses upper flange

$\leftarrow$ Shear stresses webs

— Vertical accelerations

Figure 13: Unity checks for a bridge span of 6, 12, 18 and $24 \mathrm{~m}$ (L/250, TC3, CC2, 0.5\%) 
From Figure 13, two normative requirements can be put forward when designing a GFRP webcore footbridge with the proposed criteria, namely the deflection under the evenly distributed load for bridges with a small span $(<12 \mathrm{~m})$ and the vertical acceleration for bridges with a larger span ( $\geq 12 \mathrm{~m}$ ). Obviously, this boundary will shift when applying other deflection or acceleration limits. It can also be deduced from the graphs that the achievable depth to span ratio will decrease as the span of the bridge increases. As mentioned earlier, it can be seen that the strength of the flanges and web plates is typically not a problem in the design of the footbridge.

Figure 14 shows the structural mass per square meter, i.e. the mass of the bridge deck without the surfacing layer and the handrail, as a function of the depth to span ratio for different spans with the boundary conditions and criteria specified in the design example above. The red lines represent the upper and lower limits of the thickness of the flanges.

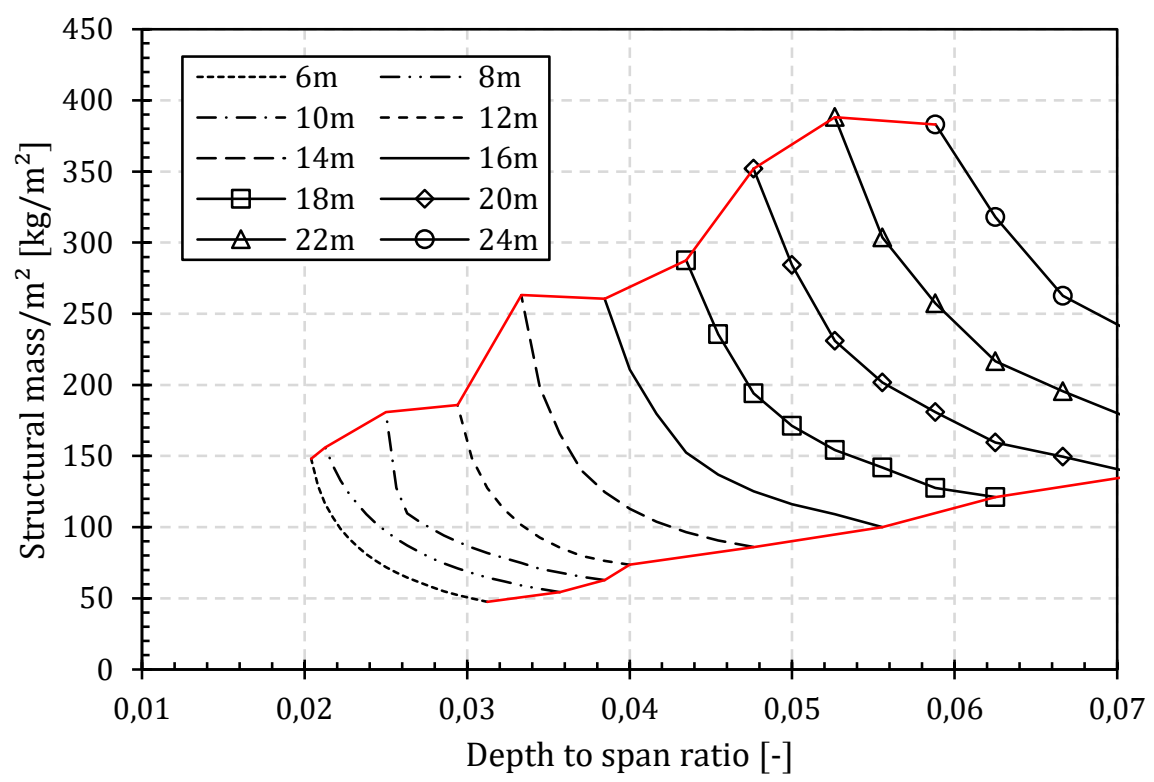

Figure 14: Structural mass per square meter as a function of the depth to span ratio for different bridge spans (L/250, TC3, CC2, 0.5\%)

\subsubsection{First natural frequency as a function of the depth to span ratio}

Figure 15 shows, for the given criteria, the calculated first natural frequencies. A decreasing trend in the natural frequency can be found as the span length increases. As a result, the comfort of the bridge will play a greater role for longer bridges, as could also be deduced from the graphs with the unity checks in Figure 13. 


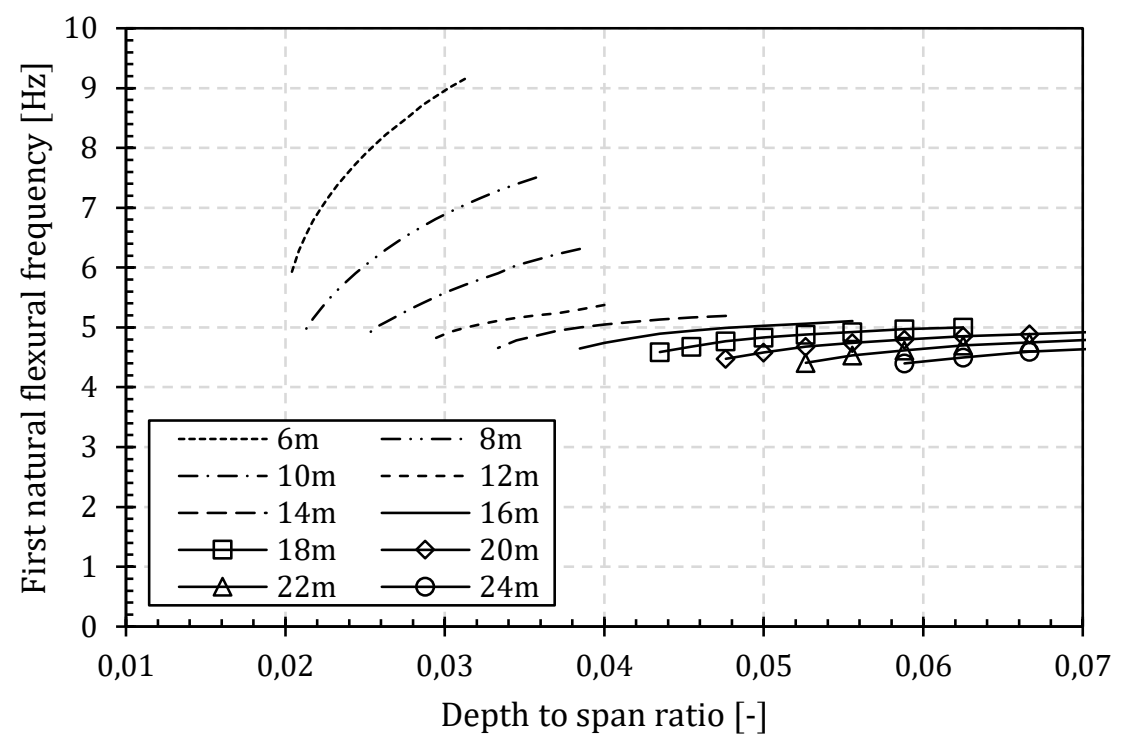

Figure 15: Evolution of the first natural flexural frequency for different bridge spans $(\mathrm{L} / 250, \mathrm{TC} 3, \mathrm{CC}, 0.5 \%)$

\subsubsection{Influence of the comfort criterion}

Figure 16 shows a comparison of the structural mass per square meter for different bridge spans based on comfort requirements CC2 (medium comfort) and CC4 (no comfort requirement) [32].

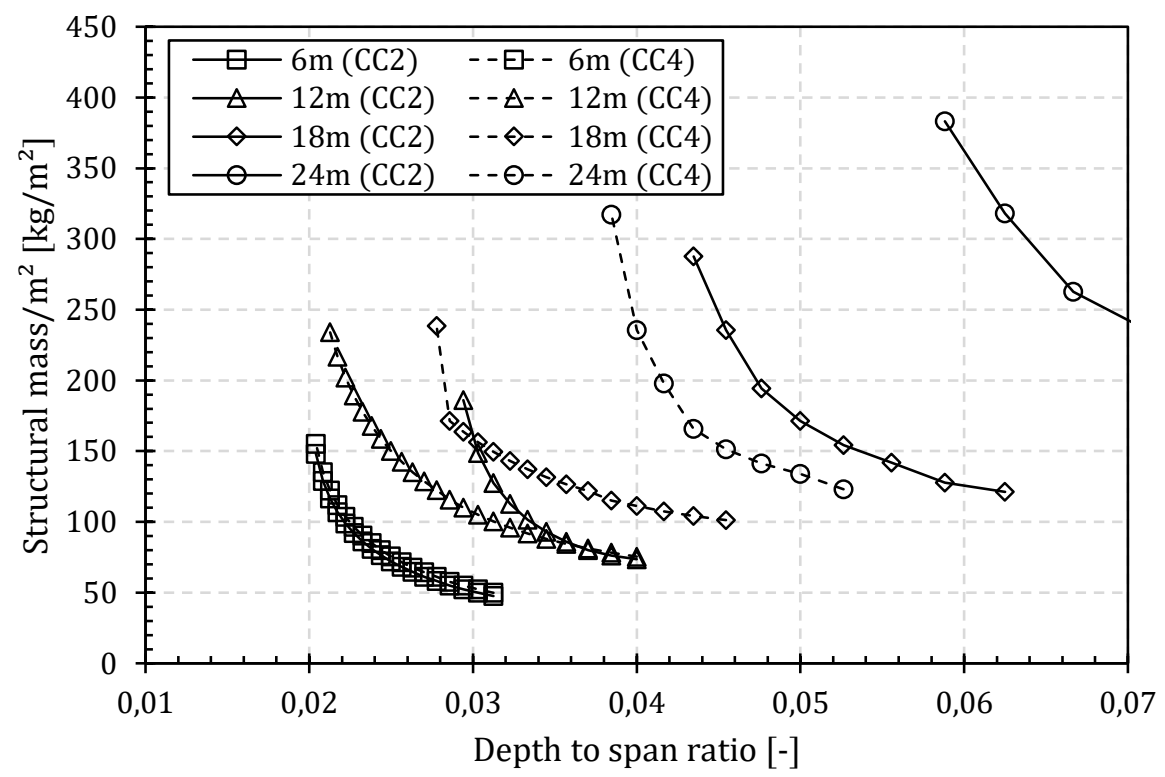

Figure 16: Comparison in structural mass per square meter for a design based on CC2 and CC4 for different bridge spans (L/250, TC3, 0.5\%)

Figure 16 provides insight on the relevance of the comfort criteria for different spans. Firstly, for the $6 \mathrm{~m}$ span, the comfort requirement is irrelevant, since the design is dominated by the deflection criterion as could already be seen in Figure 13. Secondly, for the $12 \mathrm{~m}$ span, the comfort requirement is relevant for depth to span ratios lower than $0,036(1 / 28)$, rapidly increasing the structural mass. Finally, for the 18 and $24 \mathrm{~m}$ spans, the comfort requirement quickly makes a competitive GFRP web-core panel bridge design impossible at excessively small depth to span ratios and excessively large material consumptions. 


\subsubsection{Influence of the damping ratio}

Figure 17 plots a comparison of the structural mass per square meter for a design using a damping ratio of $0.5 \%$ and $4.5 \%$.

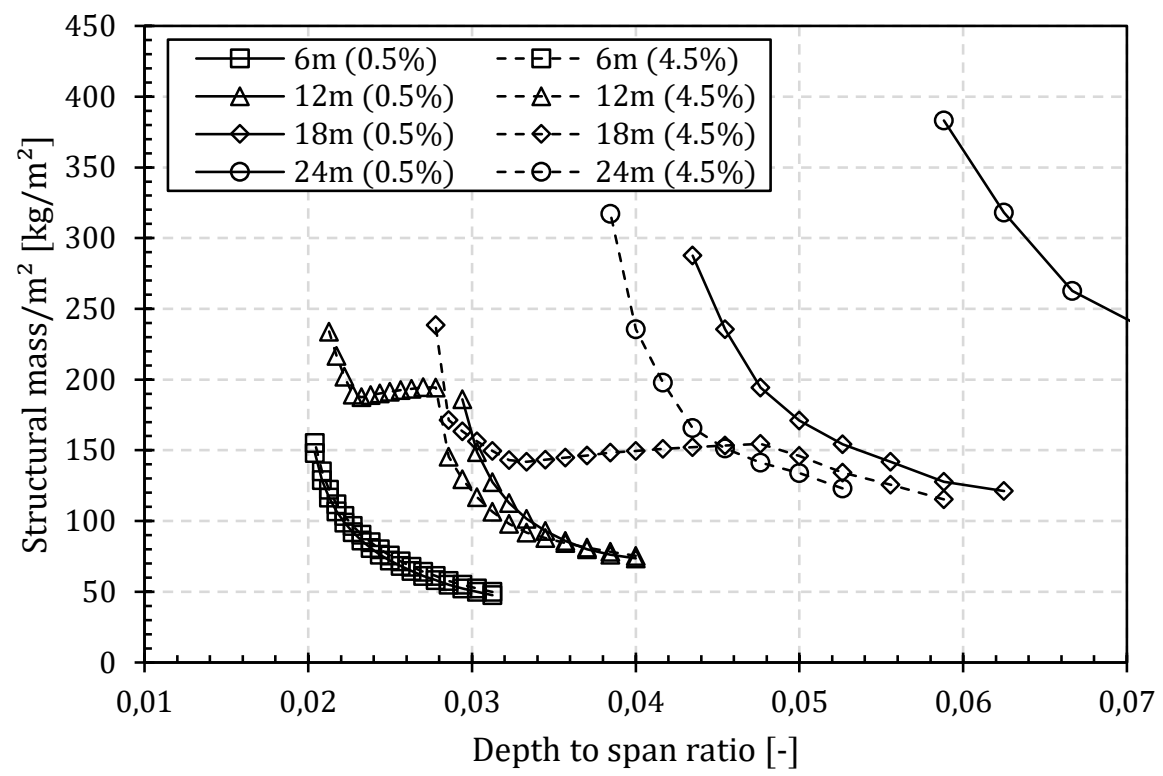

Figure 17: Comparison in structural mass per square meter for a design based on damping ratio of $0.5 \%$ and $4.5 \%$ for different bridge spans (L/250, TC3, CC2)

By applying an increased damping ratio of $4.5 \%$ in the design of a GFRP web-core footbridge, it will be possible to design slimmer bridges with the same structural mass per square meter. For example, a bridge with a span of $18 \mathrm{~m}$ and a structural mass of $150 \mathrm{~kg} / \mathrm{m}^{2}$ can be designed with a depth to span ratio of $0.040(1 / 25)$ if a damping ratio of $4.5 \%$ is used, while for a damping ratio of $0.5 \%$ a depth to span ratio of $0.053(1 / 19)$ is achieved, which equates to a magnification of $32.5 \%$ of the cross section of the bridge. Again it should be pointed out that for the smaller spans, the deflection criterion is dominant, and the increase of the damping ratio has little effect.

\subsubsection{Influence of the width}

Figure 18 shows the influence of the useful width on the structural mass in the design of a GFRP web-core footbridge. 


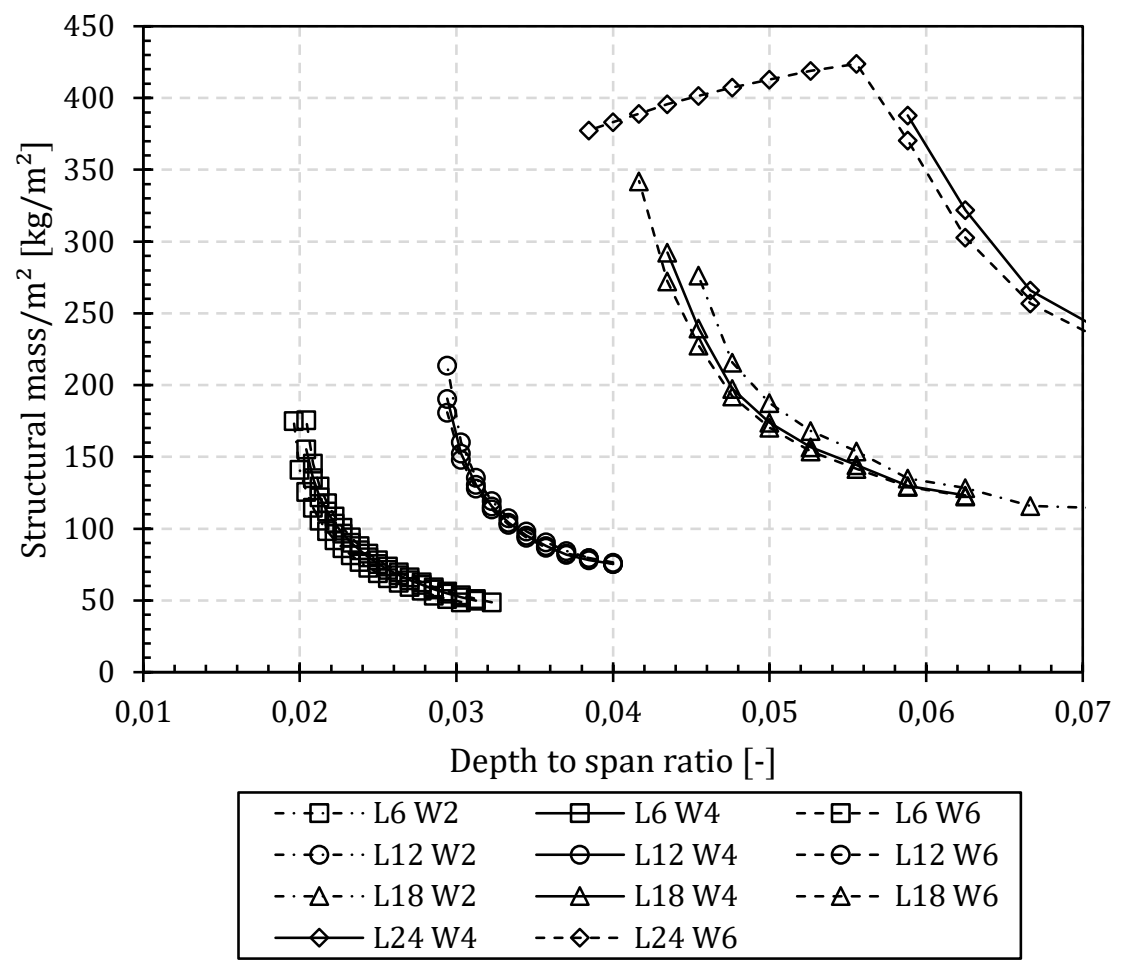

Figure 18: Influence of the useful width in the design of a GFRP web-core footbridge $(\mathrm{L} / 250, \mathrm{TC} 3, \mathrm{CC}, 0.5 \%)$

The width has only a limited influence on the structural mass and the achievable depth to span ratio in the design of a GFRP web-core footbridge. For the bridge with a span of $24 \mathrm{~m}$ and a useful width of $6 \mathrm{~m}$ (L24 W6), the structural mass for depth to span ratios larger than $0.055(1 / 18)$ will decrease, as the first natural flexural frequency with a pedestrian traffic will be greater than 4.2 $\mathrm{Hz}$, so that a reduction coefficient smaller than 0.25 will be applied. Furthermore, with a span of $24 \mathrm{~m}$, it will not be possible to design a bridge with a useful width of $2 \mathrm{~m}$ as the thickness of the flanges will exceed the maximum thickness. All in all, the influence of the width is limited, and only a consequence of the cross section edges and the ratio $B_{u s e} / B_{b}$.

\subsubsection{Influence of surfacing and handrail}

Figure 19 shows the influence of the non-structural mass of the surfacing and the handrail in the design of a GFRP web-core footbridge. It should be noted that in this calculation, the surfacing and the handrail are entirely non-structural. Whether this is the case in reality can only be determined by testing. Even then, caution should be used, as temperature or time dependent behaviour of the surfacing or handrail may be difficult to assess.

A bituminous surfacing with a thickness of $15 \mathrm{~mm}$ and a specific density of $1700 \mathrm{~kg} / \mathrm{m}^{3}$ and a stainless steel handrail with a mass of $10 \mathrm{~kg}$ per meter will be used. The thickness of the surfacing and mass per meter of the handrail will be noted in the legend of the figure as (S15 HR10) vs (S0 HR0) for the situation without surfacing and handrail. 


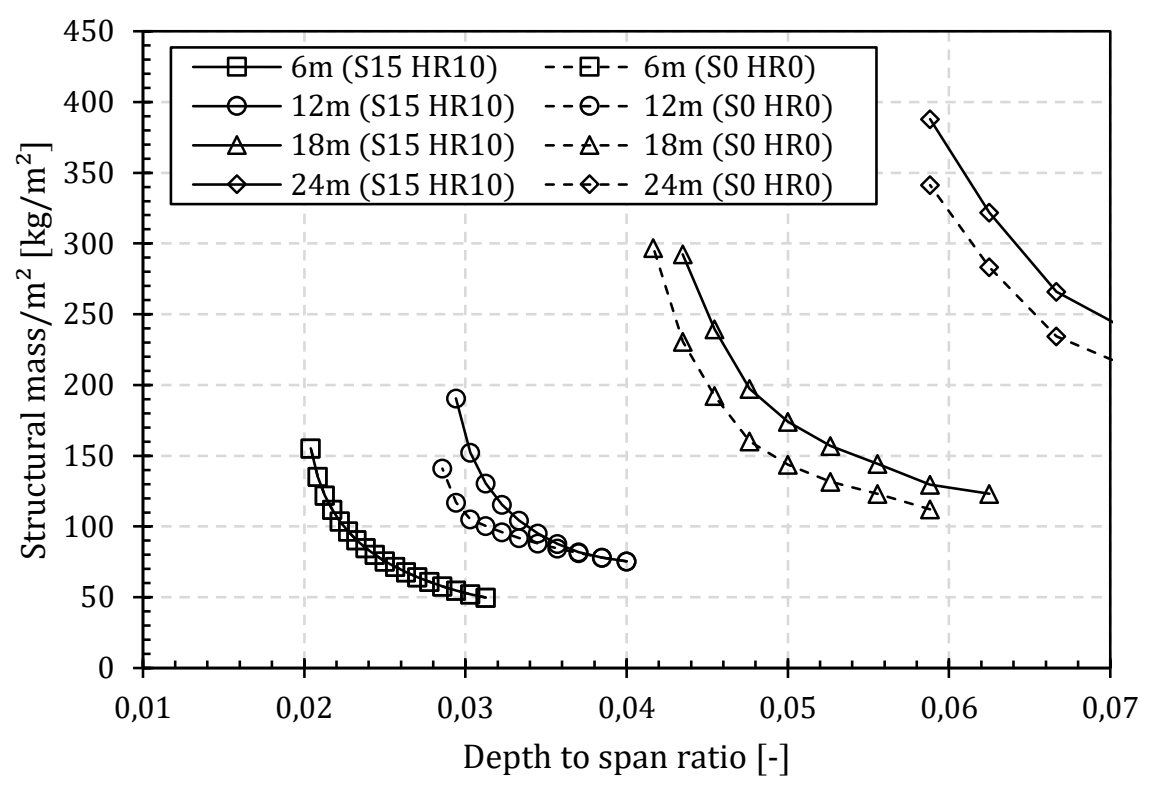

Figure 19: Influence of non-structural mass of the surfacing and handrail on the structural mass of the bridge (L/250, TC3, CC2, 0.5\%)

If the deflection under a uniformly distributed load is the determining criterion in the design of the GFRP web-core footbridge, such as for a span of $6 \mathrm{~m}$ and for depth to span ratios larger than $0.037(1 / 27)$ for a span of $12 \mathrm{~m}$, the addition of non-structural mass due to the surfacing and the handrail does not affect the structural mass per square meter of the bridge. However, the mass of the surfacing and handrail will have a minor influence on the structural mass per square meter if the design is determined by the vertical acceleration (comfort), as is the case for a span of $24 \mathrm{~m}$, $18 \mathrm{~m}$ and for depth to span ratios smaller than $0.037(1 / 27)$ at a span of $12 \mathrm{~m}$.

For a span of $18 \mathrm{~m}$ and a depth to span ratio of $0.050(1 / 20)$, the structural mass per square meter of the GFRP web-core footbridge will increase with $20.8 \%$ from $144 \mathrm{~kg} / \mathrm{m}^{2}$ to $174 \mathrm{~kg} / \mathrm{m}^{2}$ if a surfacing and a handrail are adopted in the design of the bridge. This increase in structural mass is mainly due to a thickening of the flanges and webs to accommodate the comfort requirement of CC2.

Contrary perhaps to common belief, the study indicates that purely non-structural surfacing and hand railing have a negative impact on the comfort analysis and will increase the structural material consumption of FRP web-core footbridges.

\subsubsection{Influence of boundary conditions}

The influence of the boundary conditions on the structural mass per square meter can be found in Figure 20, where a comparison is made between a simply supported (SS) bridge and a double clamped/fully fixed (FF) bridge. 


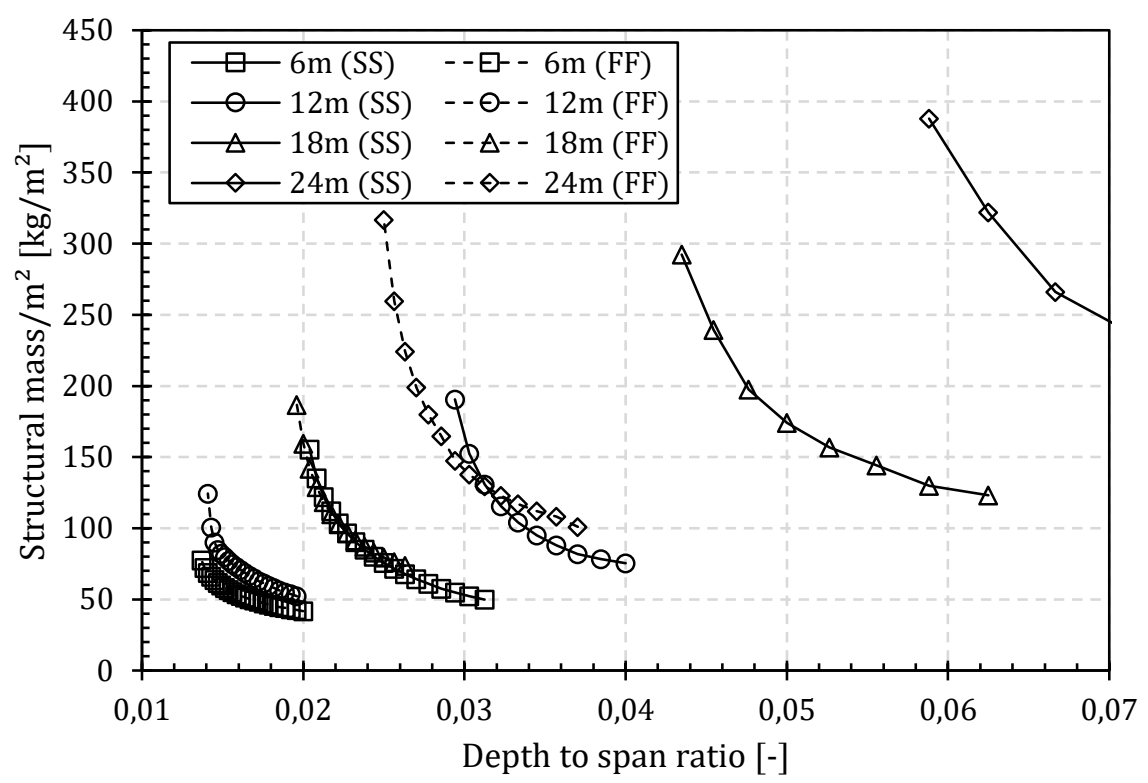

Figure 20: Comparison between the structural mass of a bridge with simply supported (SS) and fully fixed/double clamped (FF) boundary conditions for various bridge spans (L/250, TC3, CC2, 0.5\%)

Adjusting the boundary conditions for a double clamped bridge will have a major impact on the feasible depth to span ratio and structural mass of the bridge. It is clear that a greater depth to span ratio can be obtained when switching from a simply supported boundary condition to a double clamped bridge. For example, with the same structural mass of approximately $150 \mathrm{~kg} / \mathrm{m}^{2}$, a bridge with a span of $18 \mathrm{~m}$ can be constructed with a depth to span ratio of $0.053(1 / 19)$ if it is simply supported, while a depth to span ratio of $0.020(1 / 50)$ is obtained if it is double clamped.

A designer should, however, be fully aware that a double clamped footbridge has serious consequences regarding the design of the abutments, and should be extended lengthwise to accommodate the clamping forces. This is not taken into account in the current study, which only considers the structural mass in the free span.

\subsubsection{Influence of the traffic class}

The influence of the traffic classes TC1 $\left(0.1 \mathrm{P} / \mathrm{m}^{2}\right)$, TC3 $\left(0.5 \mathrm{P} / \mathrm{m}^{2}\right)$ and TC4 $\left(1.0 \mathrm{P} / \mathrm{m}^{2}\right)$ [32] is examined in this section for various bridge spans. 


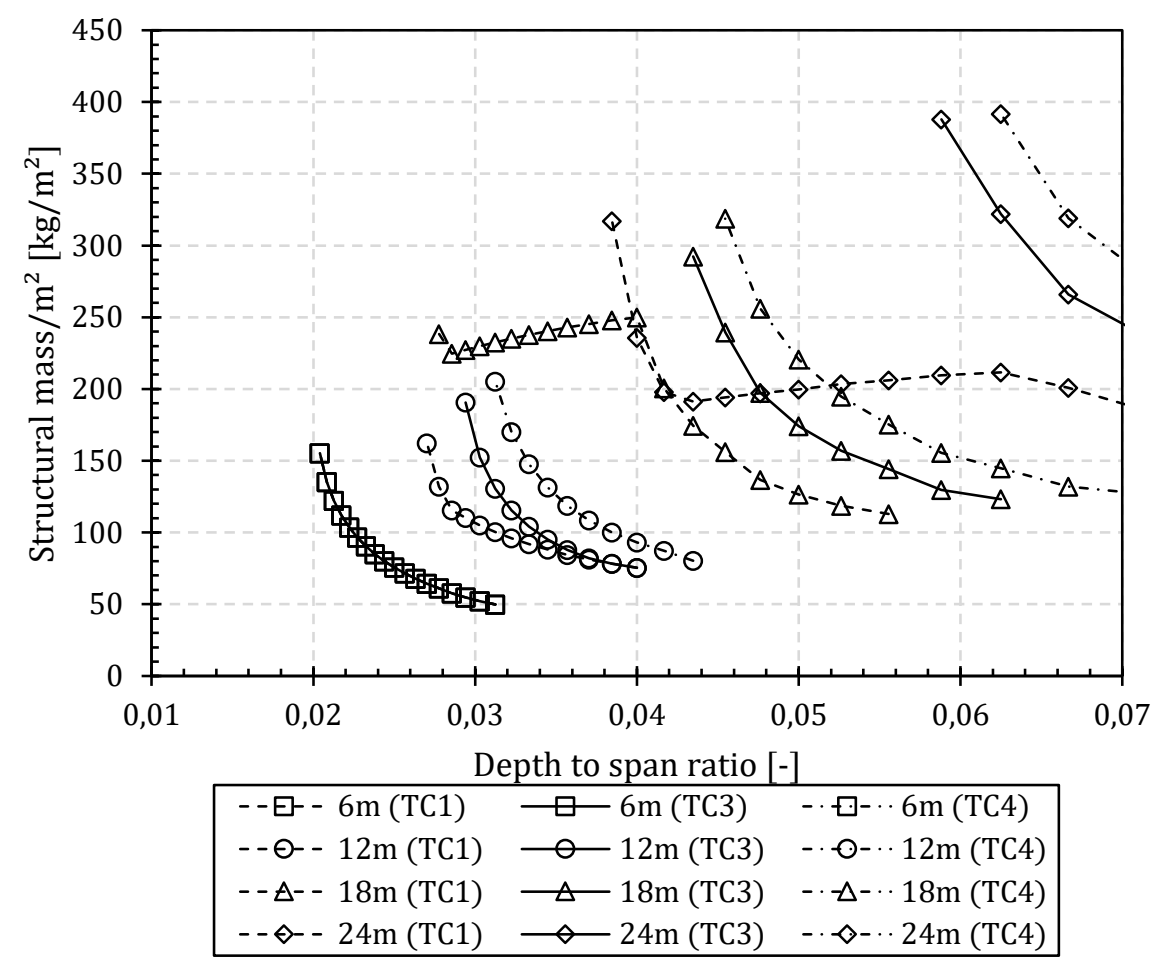

Figure 21: Comparison of the influence of a pedestrian traffic class TC1 $\left(0.1 \mathrm{P} / \mathrm{m}^{2}\right), \mathrm{TC} 3\left(0.5 \mathrm{P} / \mathrm{m}^{2}\right)$ and TC4 $(1.0$ $\mathrm{P} / \mathrm{m}^{2}$ ) on the structural mass per square meter $(\mathrm{L} / 250, \mathrm{CC} 2,0.5 \%)$

By setting a lower traffic class and associated pedestrian density, it will be possible to design a lighter and more slender bridge. For example, for a bridge with a span of $18 \mathrm{~m}$ and a depth to span ratio of $0.050(1 / 20)$, the structural mass will decrease from $220 \mathrm{~kg} / \mathrm{m}^{2}$ for TC4 $\left(1.0 \mathrm{P} / \mathrm{m}^{2}\right)$ to a structural mass of $174 \mathrm{~kg} / \mathrm{m}^{2}$ and $126 \mathrm{~kg} / \mathrm{m}^{2}$ for respectively a TC3 $\left(0.5 \mathrm{P} / \mathrm{m}^{2}\right)$ and TC1 $(0.1$ $\left.\mathrm{P} / \mathrm{m}^{2}\right)$.

In addition, the limit of $4.2 \mathrm{~Hz}$ for the first natural flexural frequency in loaded condition for a pedestrian traffic will be reached more quickly, making it possible, for example, for bridges with a span of $18 \mathrm{~m}$ and $24 \mathrm{~m}$ to be designed with a decreased depth to span ratio. Consequently, with decreasing depth to span ratio, the deflection requirement under a uniformly distributed load will become more important to the detriment of the comfort requirement.

\section{Conclusions}

This paper reports a parametric study on the influence of the serviceability limit state (SLS) design requirements (i.e. the maximum live load deflection, the minimum first flexural vibration frequency, the pedestrian comfort class) on the material consumption and self-weight of web-core sandwich panel FRP composite footbridges. Little publicly available information provides guidance into the relevant influential factors in the design, especially the material consumption in relation to the overall dimensions, the depth to span ratio, the presence of non-structural elements (surfacing, hand railing), and the design requirements. The paper describes the initial design process of a typical web-core sandwich panel footbridge, focussing on the relevance of the various design checks (SLS, ULS, accidental) on the overall material consumption at a given depth to span ratio. It is clear that over a wide range of input parameters, only the SLS requirements are relevant for the design of this bridge type, as could be derived from the unity checks for various span and depth to span ratio values. Consequently, the final material consumption and achievable depth to span ratio strongly depends on the code requirements. These requirements are nonuniform over various international codes, but are shown to have a huge influence on the material 
consumption. For small spans $(<10 \mathrm{~m})$, typically the live load deflection criterion is dominant and its choice determines the material consumption. For large spans $(>15 \mathrm{~m})$, typically the comfort criterion is dominant, and for intermediate spans, both criteria can become dominant. It should be noted, however, that the final results heavily depend on the input value of the damping factor, which should be taken conservatively $(0,5-1 \%)$ if no other test based value is available. In addition, human induced damping is not included in current design procedures, which may lead to a significant underestimation of the effective damping, especially for the higher traffic classes, and consequently to over-design and excessive material consumption. The results contribute to understanding the mechanical behaviour of this promising bridge type, point to the relevance of the choice of SLS requirements in codes and to the lack of fully understanding the vibrational behaviour currently adopted in calculation models, possibly leading to over-conservative designs. The authors are aware that their findings are valid only for the particular geometrical, structural and materials constraints, assumed in the parametric study, and that other parameters, not considered by the authors, could be decisive in the design process.

\section{Acknowledgement}

This research was financially supported by the TETRA Project C-Bridge (Composite Bridges Roadmap into Design, Guidelines and Execution), funded by the Flemish Agency for Innovation and Entrepreneurship (VLAIO).

\section{Data availability}

The raw/processed data required to reproduce these findings cannot be shared at this time as the data also forms part of an ongoing study.

\section{References}

[1] Zoghi M. The international handbook of FRP composites in civil engineering. 2014

[2] Hollaway LC. A review of the present and future utilisation of FRP composites in the civil infrastructure with reference to their important in-service properties. Constr Build https://doi.org/10.1016/j.conbuildmat.2010.04.062.

[3] Siwowski T, Kaleta D, Rajchel M. Structural behaviour of an all-composite road bridge. Compos Struct 2018;192:555-67. https://doi.org/10.1016/j.compstruct.2018.03.042.

[4] Siwowski T, Rajchel M, Kulpa M. Design and field evaluation of a hybrid FRP composite - Lightweight concrete road bridge. Compos Struct 2019;230:111504. https://doi.org/10.1016/j.compstruct.2019.111504.

[5] Tuakta C, Of M, In E. Use of Fiber Reinforced Polymer Composite in Bridge Structures By Submitted To the Department of Civil and Environmental Engineering in Fullfillment of the Requirement for the Degree of Master of Engineering in Civil and Environmental Engineering At the M 2005.

[6] Van Den Einde L, Zhao L, Seible F. Use of FRP composites in civil structural applications. Constr. Build. Mater., 2003. https://doi.org/10.1016/S0950-0618(03)00040-0.

[7] De Corte W, Uyttersprot J, Somers R. FRP bridges in the Flanders region : Experiences from the C-bridge project 2020.

[8] Smits J. Fiber-Reinforced Polymer Bridge Design in the Netherlands: Architectural Challenges toward Innovative, Sustainable, and Durable Bridges. Engineering 2016. https://doi.org/10.1016/J.ENG.2016.04.004.

[9] Sonnenschein R, Gajdosova K, Holly I. FRP Composites and their Using in the Construction of Bridges. Procedia Eng., 2016. https://doi.org/10.1016/j.proeng.2016.08.665.

[10] Wei X, Russell J, Živanović S, Toby Mottram J. Measured dynamic properties for FRP footbridges and their critical comparison against structures made of conventional construction materials. Compos Struct 2019. https://doi.org/10.1016/j.compstruct.2019.110956.

[11] Tuwair H, Drury J, Volz J. Testing and evaluation of full scale fiber-reinforced polymer bridge deck panels incorporating a polyurethane foam core. Eng Struct 2019;184:205-16. https://doi.org/10.1016/j.engstruct.2019.01.104.

[12] Wan B. Using fiber-reinforced polymer (FRP) composites in bridge construction and monitoring their performance: An overview. Adv. Compos. Bridg. Constr. Repair, Elsevier Inc.; 2014, p. 3-29. https://doi.org/10.1533/9780857097019.1.3.

[13] Siwowski T, Kulpa M, Rajchel M, Poneta P. Design, manufacturing and structural testing of all-composite FRP bridge girder. 
Compos Struct 2018;206:814-27. https://doi.org/10.1016/j.compstruct.2018.08.048.

[14] Klasztorny M, Zajac KP, Nycz DB. GFRP composite footbridge series with multi-box cross section - Part 1: Design methodology, conceptual design and global detailed design. Compos Struct 2020;238:111965. https://doi.org/10.1016/j.compstruct.2020.111965

[15] Mara V, Haghani R, Harryson P. Bridge decks of fibre reinforced polymer (FRP): A sustainable solution. Constr Build Mater 2014. https://doi.org/10.1016/j.conbuildmat.2013.09.036.

[16] Zyjewski A, Chróścielewski J, Pyrzowski Ł. The use of fibre-reinforced polymers (FRP) in bridges as a favourable solution for the environment. E3S Web Conf 2017;17. https://doi.org/10.1051/e3sconf/20171700102.

[17] Kim YJ. State of the practice of FRP composites in highway bridges. Eng Struct 2019. https://doi.org/10.1016/j.engstruct.2018.10.067.

[18] Manalo A, Aravinthan T, Fam A, Benmokrane B. State-of-the-art Revieuw on FRP sandwich systems for lightweight civil infrasyructure. Compos Constr 2017;21.

[19] Tuwair H, Hopkins M, Volz J, ElGawady MA, Mohamed M, Chandrashekhara K, et al. Evaluation of sandwich panels with various polyurethane foam-cores and ribs. Compos Part B Eng 2015;79:262-76. https://doi.org/10.1016/j.compositesb.2015.04.023.

[20] De Corte W, Jansseune A, Van Paepegem W, Peeters J. Structural behaviour and robustness assessment of an InfraCore ${ }^{\circledR}$ inside bridge deck specimen subjected to static and dynamic local loading. ICCM Int Conf Compos Mater 2017;2017Augus:20-5.

[21] De Corte W, Jansseune A, Van Paepegem W, Peeters J. Elastic properties and failure behavior of tiled laminate composites. Key Eng Mater 2018;774 KEM:564-9. https://doi.org/10.4028/www.scientific.net/KEM.774.564.

[22] Karbhari VM. Material Considerations in FRP Rhabilitation of concrete structures. J Mater Civ Eng 2001;13:90-7.

[23] Berardi VP, Perrella M, Feo L, Cricrì G. Creep behavior of GFRP laminates and their phases: Experimental investigation and analytical modeling. Compos Part B Eng 2017;122:136-44. https://doi.org/10.1016/j.compositesb.2017.04.015.

[24] Chróścielewski J, Miśkiewicz M, Pyrzowski Ł, Sobczyk B, Wilde K. A novel sandwich footbridge - Practical application of laminated composites in bridge design and in situ measurements of static response. Compos Part B Eng 2017;126:153-61. https://doi.org/10.1016/j.compositesb.2017.06.009.

[25] Vovesný M, Rotter T. GFRP bridge deck panel. Procedia Eng 2012;40:492-7. https://doi.org/10.1016/j.proeng.2012.07.131.

[26] Stankiewicz B. Composite GFRP deck for bridge structures. Procedia Eng 2012;40:423-7. https://doi.org/10.1016/j.proeng.2012.07.119.

[27] EuCIA. Prospect for New Guidance in the Design of FRP Structures. 2016

[28] Clarke JL. Structural design of polymer composites - Eurocomp design code and handbook. 1996.

[29] CIRIA C779. Fibre-reinforced polymer bridges - Guidance for designers. 2018.

[30] The Highways Agency. BD 90/05 Design of FRP Bridges and Highway Structures. Des Man Roads Bridg Highw Struct Approv Proced Gen Des 2005;1:21.

[31] CROW. Aanbevelingen 96:2019 Vezelversterkte kunststoffen in bouwkundige en civieltechnische draagconstructiesfile 2019:194. https://doi.org/9789066286726.

[32] JRC Scientific and Technical. Design of Lightweight Footbridges for Human Induced Vibrations. 2009. https://doi.org/10.1088/1751-8113/44/8/085201.

[33] Van Nimmen K, Lombaert G, De Roeck G, Van den Broeck P. Vibration serviceability of footbridges: Evaluation of the current codes of practice. Eng Struct 2014;59:448-61. https://doi.org/10.1016/j.engstruct.2013.11.006.

[34] Van Nimmen K, Lombaert G, de Roeck G, Van Den Broeck P. Human-induced vibrations of footbridges: The effect of vertical human-structure interaction. Conf Proc Soc Exp Mech Ser 2016;4:299-307. https://doi.org/10.1007/978-3-319-29763729.

[35] Van Nimmen K, Lombaert G, De Roeck G, Van den Broeck P. The impact of vertical human-structure interaction on the response of footbridges to pedestrian excitation. J Sound Vib 2017;402:104-21. https://doi.org/10.1016/j.jsv.2017.05.017.

[36] European Committee For Standerdization. EN 1990:2002 - Basis of structural design. vol. 1. 2011.

[37] Hsiao K-T, Heider D. Vacuum assisted resin transfer molding (VARTM) in polymer matrix composites. Woodhead Publishing Limited; 2012. https://doi.org/10.1533/9780857096258.3.310.

[38] Shokrieh MM, Moshrefzadeh-Sani H. On the constant parameters of Halpin-Tsai equation. Polymer (Guildf) 2016;106:14-20. https://doi.org/10.1016/j.polymer.2016.10.049.

[39] Abdel Ghafaar, M. (Design and Production Engineering Department, Faculty of Engineering, Minia University, Minia E, ElMahallawy, N. A. (Production Engineering Department, Faculty of Engineering, Ain Shams University, Cairo E. Application of the rule of mixture and Halpin-Tsai equations to woven fabric reinforced epoxy composites 2005;34:227-36.

[40] Patterson W, Force A. The Halpin-Tsai Equations: A Review 1976;16.

[41] Giner E, Vercher A, Marco M, Arango C. Estimation of the reinforcement factor $\xi$ for calculating the transverse stiffness E2 with the Halpin-Tsai equations using the finite element method. Compos Struct 2015;124:402-8. 
https://doi.org/10.1016/j.compstruct.2015.01.008.

[42] Pendleton RL, Tuttle ME. Manual on Experimental Methods for Mechanical Testing of Composites. Elsevier Applied Science Publishers; 1989.

[43] Technische Universität Dresden, Institute of Aerospace Engineering C of AE. eLamX² - expandable Laminate explorer 2020. https://tu-dresden.de/ing/maschinenwesen/ilr/lft/elamx2/elamx.

[44] European commitee for Standerization. EN 1991-2:2003 - Traffic loads on bridges. vol. 1. 2003.

\section{Figure captions}

Figure 1: Schematic representation of the content of this paper

Figure 2: Detailed top and cross-sectional graphical representation of the dimensions and build-up of the design model

Figure 3: $\mathrm{k}_{1}$ and $\mathrm{k}_{2}$ values as function of the first natural flexural frequency for different pedestrian traffics

Figure 4: Reduction coefficient for the design vertical acceleration [31]

Figure 5: Evolution of the unity checks and limiting values as a function of the depth to span ratio of the calculation example with a bridge span of $16 \mathrm{~m}(\mathrm{~L} / 250, \mathrm{TC} 3, \mathrm{CC} 2,0.5 \%)$

Figure 6: Structural mass per square meter for various deflection criteria and a medium comfort requirement (TC3, CC2, 0.5\%)

Figure 7: Structural mass per square meter for various deflection criteria and without a comfort requirement (TC3, CC4, 0.5\%)

Figure 8: Structural mass per square meter as a function of the depth to span ratio and the comfort criterion for a bridge span of $16 \mathrm{~m}$ and different damping ratios (L/250, TC3)

Figure 9: Evolution of the first natural flexural frequency in loaded condition (left) and thickness of the upper flange (right) for a bridge span of $16 \mathrm{~m}$ and CC3

Figure 10: Unity checks for a bridge span of $16 \mathrm{~m}$ and CC3

Figure 11: Structural mass per square meter as a function of the depth to span ratio and the structural damping ratio for a bridge span of $16 \mathrm{~m}(\mathrm{~L} / 250, \mathrm{TC} 3, \mathrm{CC} 2)$

Figure 12: Unity checks for a bridge span of $16 \mathrm{~m}$ and a damping ratio of $4.5 \%$

Figure 13: Unity checks for a bridge span of 6, 12, 18 and $24 \mathrm{~m}$ (L/250, TC3, CC2, 0.5\%)

Figure 14: Structural mass per square meter as a function of the depth to span ratio for different bridge spans (L/250, TC3, CC2, 0.5\%)

Figure 15: Evolution of the first natural flexural frequency for different bridge spans (L/250, TC3, CC2, 0.5\%)

Figure 16: Comparison in structural mass per square meter for a design based on CC2 and CC4 for different bridge spans (L/250, TC3, $0.5 \%)$

Figure 17: Comparison in structural mass per square meter for a design based on damping ratio of $0.5 \%$ and $4.5 \%$ for different bridge spans (L/250, TC3, CC2)

Figure 18: Influence of the useful width in the design of a GFRP web-core footbridge (L/250, TC3, CC2, 0.5\%)

Figure 19: Influence of non-structural mass of the surfacing and handrail on the structural mass of the bridge (L/250, TC3, CC2, 0.5\%)

Figure 20: Comparison between the structural mass of a bridge with simply supported (SS) and fully fixed/double clamped (FF) boundary conditions for various bridge spans (L/250, TC3, CC2, $0.5 \%$ )

Figure 21: Comparison of the influence of a pedestrian traffic class TC1 $\left(0.1 \mathrm{P} / \mathrm{m}^{2}\right)$, TC3 $\left(0.5 \mathrm{P} / \mathrm{m}^{2}\right)$ and TC4 $\left(1.0 \mathrm{P} / \mathrm{m}^{2}\right)$ on the structural mass per square meter $(\mathrm{L} / 250, \mathrm{CC} 2,0.5 \%)$

\section{Table captions}

Table 1: Main properties of the constituent materials [31]

Table 2: Partial material factor for the specific resistance [31]

Table 3: Conversion factors for the different assessment aspects in ULS and SLS [31]

Table 4: Traffic loads on GFRP web-core footbridge

Table 5: Accidental loads on GFRP web-core footbridge

Table 6: Pedestrian traffic classes and densities [33]

Table 7: Comfort classes with vertical acceleration ranges [33]

Table 8: Constants for the vertical acceleration with a pedestrian density of less than or equal to $0.5 \mathrm{P} / \mathrm{m}^{2}$

Table 9: Summary bridge dimensions calculation example 
Table 10: Characteristic values of a single UD E-glass/polyester composite layer

Table 11: Construction of the various laminates in the bridge

Table 12: Equivalent stiffness and strength for the laminates in the bridge

Table 13: Permanent loads on GFRP pedestrian and bicycle bridge

Table 14: First natural flexural frequency for five traffic classes

Table 15: Results for vertical acceleration and comfort class with a structural damping ratio of $0.5 \%$ and $1.0 \%$ for different traffic classes 